\title{
Intercomparison and assessment of turbulent and physiological exchange parameters of grassland
}

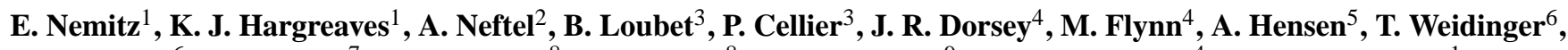 \\ R. Meszaros $^{6}$, L. Horvath ${ }^{7}$, U. Dämmgen ${ }^{8}$, C. Frühauf ${ }^{8}$, F. J. Löpmeier ${ }^{9}$, M. W. Gallagher ${ }^{4}$, and M. A. Sutton ${ }^{1}$ \\ ${ }^{1}$ Atmospheric Sciences, Centre for Ecology and Hydrology (CEH) Edinburgh, Bush Estate, Penicuik, Midlothian, \\ EH26 0QB, UK \\ ${ }^{2}$ Swiss Federal Research Station for Agroecology and Agriculture (FAL-CH), Zürich-Reckenholz and Liebefeld-Bern, \\ 3003 Bern, Switzerland \\ ${ }^{3}$ Institut National de la Recherche Agronomique (INRA), UMR Environnement et Grandes Cultures, Thiverval-Grignon, \\ 78850, France \\ ${ }^{4}$ School of Earth, Atmospheric and Environmental Sciences, University of Manchester, Simon Building, Oxford Road, \\ Manchester, M13 9PL, UK (formerly known as: University of Manchester Institute of Science and Technology, UMIST). \\ ${ }^{5}$ Energy research Centre of the Netherlands (ECN), Postbus 1, 1755 ZG Petten, The Netherlands \\ ${ }^{6}$ Eötvös Loránd University, Department of Meteorology, 1117 Budapest, Hungary \\ ${ }^{7}$ Hungarian Meteorological Service, 1675 Budapest, Hungary \\ ${ }^{8}$ Institute for Agroecology, German Agricultural Research Institute, Braunschweig-Völkerode, Germany \\ ${ }^{9}$ Agrometeorological Research Station of Deutscher Wetterdienst, Bundesallee 50, 38116 Braunschweig, Germany
}

Received: 22 September 2008 - Published in Biogeosciences Discuss.: 8 January 2009

Revised: 30 July 2009 - Accepted: 30 July 2009 - Published: 7 August 2009

\begin{abstract}
Commonly, the micrometeorological parameters that underline the calculations of surface atmosphere exchange fluxes (e.g. friction velocity and sensible heat flux) and parameters used to model exchange fluxes with SVATtype parameterisations (e.g. latent heat flux and canopy temperature) are measured with a single set of instrumentation and are analysed with a single methodology. This paper evaluates uncertainties in these measurements with a single instrument, by comparing the independent results from nine different institutes during the international GRAMINAE integrated field experiment over agricultural grassland near Braunschweig, Lower Saxony, Germany. The paper discusses uncertainties in measuring friction velocity, sensible and latent heat fluxes, canopy temperature and investigates the energy balance closure at this site. Although individual 15-min flux calculations show a large variability between the instruments, when averaged over the campaign, fluxes agree within $2 \%$ for momentum and $11 \%$ for sensible heat. However, the spread in estimates of latent heat flux $(\lambda E)$ is
\end{abstract}

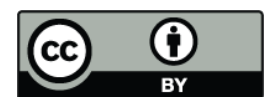

Correspondence to: E. Nemitz (en@ceh.ac.uk) larger, with standard deviations of averages of $18 \%$. The dataset averaged over the different instruments fails to close the energy budget by $20 \%$, significantly larger than the uncertainties in the individual flux corrections. However, if the largest individual turbulent flux estimates are considered, energy closure can be achieved, indicating that the closure gap is within the spread of the measurements. The uncertainty in $\lambda E$ feeds results in an uncertainty in the bulk stomatal resistance, which further adds to the uncertainties in the estimation of the canopy temperature that controls the exchange. The paper demonstrated how a consensus dataset was derived, which is used by the individual investigators to calculate fluxes and drive their models.

\section{Introduction}

When measuring surface/atmosphere exchange fluxes of trace constituents at the canopy scale, usually one single set of instrumentation is used to provide the micrometeorological information necessary for the calculation of canopy scale fluxes. The same is true for the measurement of parameters

Published by Copernicus Publications on behalf of the European Geosciences Union. 
that are used to drive parameterisations and models to predict the exchange, usually in the form of soil-vegetationatmosphere transport (SVAT) models. Key parameters are wind speed $(u)$, friction velocity $\left(u_{*}\right)$ and the sensible heat flux $(H)$ for the calculation of fluxes, while the parameterisations require input of photosynthetically active radiation (PAR) or solar radiation $\left(S_{t}\right)$, air temperature $\left(T_{a}\right)$, canopy temperature $\left(T_{c}\right)$ and relative humidity $(\mathrm{RH})$.

This paper utilises measurements made during the GRAMINAE Integrated Experiment at Braunschweig, Germany, to investigate the effect of differences between approaches and uncertainties in the results, using an array of instrumentation operated and analysed by a number of independent institutes. The main aim of the overall experiment was to investigate the dynamics of ammonia exchange between agricultural grassland and the atmosphere, as described in detail elsewhere (Sutton et al., 2009b).

The measurements included fluxes of momentum and sensible heat made with a total of ten independent ultrasonic anemometers, operated by nine different institutes from five different countries and analysed according to their respective protocols, as well as four measurements of latent heat fluxes and three measurements of net radiation. In addition, several different approaches to derive the leaf temperature were deployed during the campaign and are compared here as leaf temperature is an important parameters when parameterising or modelling biogenic emissions, e.g. of ammonia and isoprene (Sutton et al., 1995; Guenther et al., 2006).

The flux analysis techniques were deliberately not standardised, although all groups involved have extensive experience in the application of eddy-covariance techniques. Pure instrument comparisons have been presented elsewhere (e.g. Dyer et al., 1982; Tsvang et al., 1985; Fritschen et al., 1992; Christen et al., 2000; Mauder and Foken, 2001; Mauder et al., 2007, 2008). Instead, this paper focuses on the differences that may be expected to be introduced by a combination of differences in instrumentation, chosen measurement height and analysis protocols, as they would be applied by individual groups in real applications. Thus the objectives of this paper are:

1. to assess the variability in the measurements, to identify likely sources and to discuss the strengths and weaknesses of the individual approaches;

2. to quantitatively compare random errors due to turbulence statistics and systematic errors introduced by differences in the measurement approaches (instrumentation and analysis routines);

3. to assess the energy budget closure at the site;

4. to assess the performance of the aerodynamic gradient technique compared with the eddy-covariance approach;
5. to quantify uncertainties involved in the estimation of key parameters that control pollutant exchange with vegetation, such as the parameters used to parameterise stomatal conductance (derived from latent heat fluxes) and biogenic emissions (governed by leaf temperature);

6. to extrapolate the results to discuss uncertainties in standard flux measurements where only one set of sensors is available;

7. to describe how the measurements are used to derive a robust "consensus" micrometeorological datasets, with error estimates and data quality flags, which is used in the companion papers for the calculation of gradient fluxes and to drive SVAT models for reactive trace gases (Burkhardt et al., 2009; Loubet et al., 2009; Mészáros et al., 2009; Milford et al., 2009; Personne et al., 2009; Sutton et al., 2009a, b).

\section{Theory}

\subsection{Eddy-covariance approach for measuring turbulent exchange fluxes}

Several micrometeorological approaches are available to measure fluxes of momentum and heat at the canopy scale. The two approaches used here are the aerodynamic gradient method (AGM) and the eddy-covariance (EC) technique, which have extensively been described in the literature (e.g. Foken, 2008).

Eddy-covariance measures the flux $\left(F_{\chi}\right)$ of a scalar $\chi$ directly as the covariance

$F_{\chi}=\overline{w^{\prime} \chi^{\prime}}=\overline{w \chi}-\overline{w \chi}$

where $w^{\prime}$ and $\chi^{\prime}$ are the instantaneous deviations about the mean, of the vertical wind velocity $\left(\mathrm{m} \mathrm{s}^{-1}\right)$ and the scalar, respectively. For measurements above homogeneous flat terrain, $\bar{w}$ is expected to be zero and a non-zero value is usually attributed to a misalignment of the wind sensor. Therefore, a co-ordinate rotation is performed by all groups taking part in the Braunschweig experiment, to align $u$ with the mean wind.

For this study, momentum flux $(\tau)$, sensible heat flux $(H)$ and latent heat flux, $\lambda E\left(\mathrm{~W} \mathrm{~m}^{-2}\right)$ were derived directly from the eddy covariance measurements using equations equivalent to Eq. (1):

$$
\begin{aligned}
& \tau=\rho \overline{w^{\prime} u^{\prime}} \\
& H=\rho c_{p} \overline{w^{\prime} T^{\prime}} \\
& \lambda E=\frac{\lambda \rho \varepsilon}{P} \overline{w^{\prime} e^{\prime}}
\end{aligned}
$$

where $\rho$ is the density of air $\left(\mathrm{kg} \mathrm{m}^{-3}\right), c_{p}$ is the heat capacity of air $\left(\mathrm{J} \mathrm{g}^{-1} \mathrm{~K}^{-1}\right), \lambda$ is the latent heat of evaporation of water 
$\left(\mathrm{J} \mathrm{kg}^{-1}\right), \varepsilon$ is the ratio of the molecular weights of water and air $(=0.622)$ and $P$ is atmospheric pressure $(\mathrm{kPa})$.

The friction velocity $\left(u_{*}\right)$ may be calculated from the turbulence measurements as:

$u_{*}=\sqrt{-\frac{\tau}{p}}=\sqrt{-\overline{u^{\prime} w^{\prime}}}$

or

$u_{*}=\sqrt[4]{\left(\overline{u^{\prime} w^{\prime}}\right)^{2}+\left(\overline{u^{\prime} v^{\prime}}\right)^{2}}$

both of which are used by different institutes (cf. Table 2 below). In atmospheric turbulence, the covariance between the stream-wise wind component $(u)$ and the horizontal crosswind component $(v)$ is expected to be small. In addition to the previously described co-ordinate rotation around two axes, a third rotation was used here by individual groups to set this covariance to zero (Aubinet et al., 2000).

\subsection{The aerodynamic gradient approach for measuring turbulent exchange fluxes}

Eddy-covariance approaches can only applied for compounds for which fast-response sensors are available for measurement at a frequency for several Hz. For many highly reactive compounds such sensors do not generally exist, and here alternative, parameterised techniques are applied, which can utilise slow response measurements. Fluxes may be calculated as

$F_{\chi}=-u_{*} \chi_{*}$

where $u_{*}$ and $\chi_{*}$ may be derived from time-averaged gradient measurements, using the aerodynamic flux-gradient relationships (e.g. Flechard and Fowler, 1998):

$u_{*}=k \frac{d u}{d\left[\ln (z-d)-\Psi_{M}\left(\frac{z-d}{L}\right)\right]}$

and

$\chi_{*}=k \frac{d \chi}{d\left[\ln (z-d)-\Psi_{H}\left(\frac{z-d}{L}\right)\right]}$.

Note that in the literature the aerodynamic gradient approach is more often introduced in terms of a local gradient $(d \chi / d z)$ of the logarithmic profile, or the differences between two heights $\left(\left(\chi_{2}-\chi_{1}\right) /\left(z_{2}-z_{1}\right)\right)$. However, we present the approach in the (mathematically identical) form of a linear gradient (Eq. 9), as this can more easily be derived from measurements at more than two heights, by linear regression. In Eqs. (8) and (9), $k$ is von Karman's constant (0.41) and $\chi$ is the mean scalar concentration at height $(z-d), z$ is the height above the ground, $d$ is the zero-plane displacement height, and $\Psi_{M}$ and $\Psi_{H}$ are the dimensionless integrated stability correction terms for momentum and heat, which can be calculated from the height and atmospheric stability as parameterised through the Obukhov Length $(L)$ :

$L=-\frac{u_{*}^{3} \rho c_{p} T}{k g H}$, where $g$ is the acceleration due to gravity $\left(\mathrm{m} \mathrm{s}^{-2}\right)$. Various formulations for calculating the stability corrections have been presented in the literature. Here the formulations of Dyer and Hicks (1970) and Webb (1970) were used for unstable and stable conditions, respectively.

In practice, a hybrid approach is often used, where $u_{*}$ in Eq. (7) is derived by ultrasonic anemometry, while $\chi_{*}$ is derived from averaged concentration profiles according Eq. (9). This approach of a hybrid aerodynamic gradient method (HAGM) was used in a companion paper for the calculation of surface/atmosphere exchange fluxes of ammonia (Milford et al., 2009).

\subsection{Resistance analogy}

For the purposes of determining the processes controlling the exchange of scalars such as ammonia, ozone, sulphur dioxide and nitrogen oxides, it is necessary to calculate the resistances to turbulent exchange. In the case of consistently deposited species it is often assumed that the concentration of the scalar at the absorbing surface is zero such that

$R_{t}(z-d)=R_{a}(z-d)+R_{b}+R_{c}$

where $R_{t}$ is the total resistance to transfer, $R_{a}$ is the aerodynamic resistance, $R_{b}$ is the laminar boundary-layer resistance close to the surface of the leaves and $R_{c}$ is the canopy resistance. The aerodynamic resistance, $R_{a}$, at $(z-d)=1 \mathrm{~m}$ is obtained from Garland (1977):

$R_{a}(1)=\frac{u(1)}{u_{*}^{2}}-\frac{\psi_{h}\left(\frac{1}{L}\right)-\psi_{m}\left(\frac{1}{L}\right)}{k u_{*}}$

where the second r.h.s. term is zero in neutral and stable conditions. For the calculation of $R_{b}$, Owen and Thompson (1963) used the relationship

$R_{b}=\left(B u_{*}\right)^{-1}$

where $B$, the sub-layer Stanton number was defined by Garland (1977) as

$B^{-1}=1.45 R e_{*}^{0.24} S c^{0.8}$.

Here, the roughness Reynold's number, $R e_{*}$, is given by

$R e_{*}=\frac{z_{o} u_{*}}{v}$

and the Schmidt number, $S c$, by

$S c=\frac{v}{D}$

where $v$ is the kinematic viscosity of air $\left(\mathrm{m}^{2} \mathrm{~s}^{-1}\right), D$ is the diffusion coefficient of the scalar of interest $\left(\mathrm{m}^{2} \mathrm{~s}^{-1}\right)$. There are a number of alternative approaches to calculate the sublayer Stanton number (e.g. Wesely and Hicks, 1977; Sutton et al., 1993), but in practice the differences for $R_{b}$ are small 

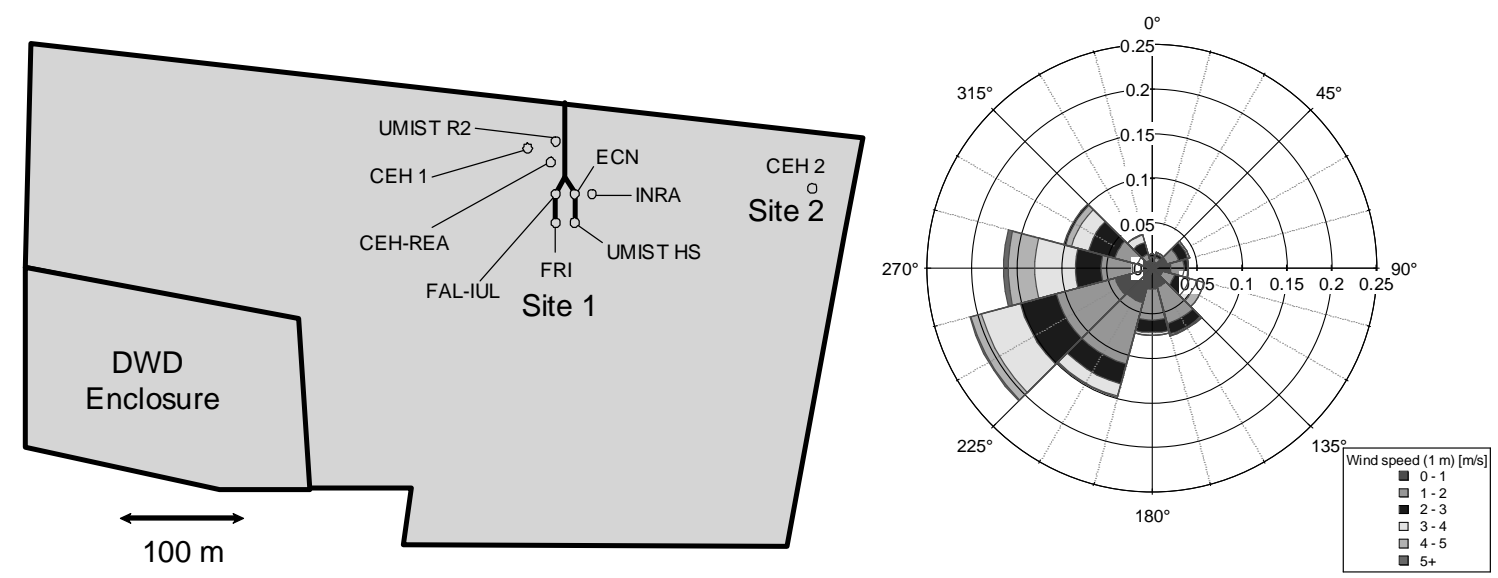

Fig. 1. Schematic of the layout of the different measurement towers on the field, together with the wind frequency distribution (by wind speed class).

for short vegetation. It should be noted that $R_{b}$ is specific for each chemical species, due to differences in $D$.

For chemical species that are exchanged with the plant through the leaf stomata, but not with the soil or leaf cuticles, $R_{c}$ may be substituted by the bulk stomatal resistance $\left(R_{s b}\right)$. In other cases, where stomatal exchange is only one of several exchange pathways, $R_{c}$ may often be represented by a resistance network which contains $R_{s b}$ (Shuttleworth and Wallace, 1985; Sutton et al., 1998; Nemitz et al., 2001). For water vapour, if it is assumed that over a transpiring canopy with dry leaf surfaces, the bulk of the latent heat flux is transported via the stomates, then it is possible to calculate a bulk stomatal resistance, $R_{s b}$, from vapour pressure at the leaf surface, $e\left(z_{0}^{\prime}\right)$ and saturated vapour pressure at the leaf surface temperature, $e_{S}\left(T\left(z_{0}^{\prime}\right)\right)$ as:

$R_{s b}=\frac{e_{s}\left(T\left(z_{0}^{\prime}\right)\right)-e\left(z_{0}^{\prime}\right)}{E}$

The surface values can be calculated for a notional mean height of the canopy exchange $\left(z_{0}^{\prime}\right)$, from the values at a reference height $\left(z_{\text {ref }}\right)$ and the turbulent fluxes, assuming the canopy to act as a big leaf:

$T\left(z_{0}^{\prime}\right)=T\left(z_{\mathrm{ref}}\right)+\frac{H}{\rho c_{p}}\left(R_{a}\left(z_{\mathrm{ref}}\right)+R_{b, H}\right)$

and

$e\left(z_{0}^{\prime}\right)=e\left(z_{\text {ref }}\right)+E\left(R_{a}\left(z_{\text {ref }}\right)+R_{b, \mathrm{H}_{2} \mathrm{O}}\right)$.

\section{Methods}

\subsection{Field site}

The field site was a Lolium perienne dominated agricultural grassland, which was cut ten days into the 27 day measurement period (19 May to 15 June 2000), from $0.7 \mathrm{~m}$ to $0.07 \mathrm{~m}$ canopy height, and which grew to $0.35 \mathrm{~m}$ by the end of the campaign. A large array of micrometeorological equipment was deployed over the canopy by several groups from different European research institutes. The bulk of this equipment was placed at "Site 1" (Fig. 1); in practice, the sensors were distributed along along a roughly north-south transect through the field, covering a distance of about $100 \mathrm{~m}$. The available fetch was approximately $300 \mathrm{~m}$ to the west and east of Site $1,200 \mathrm{~m}$ to the south and 50 to $100 \mathrm{~m}$ to the north. A further, smaller array of instruments was located at "Site 2", approximately $250 \mathrm{~m}$ east of Site 1 and close to the eastern edge of the field, which was bounded to the east by a deciduous shelterbelt approximately $8 \mathrm{~m}$ tall (Fig. 1). Figure 1 shows the layout of the different measurement masts in relation to the field boundaries and the wind frequency distribution during the campaign. In the SW corner of the field was the enclosure of the German Weather Service (DWD), which consisted of a patchwork of small grass plots with varying roughness height and water status. The participating research groups and the abbreviations used for each have been presented elsewhere, together with further details on the field site (surroundings, as well as position of scaffolding towers and mobile laboratory) and site management (Hensen et al., 2009; Sutton et al., 2009b).

\subsection{Instrumentation deployment}

The measurements analysed here were made at nine eddy flux towers, all of which were equipped with an ultrasonic anemometer to measure fluxes of momentum and sensible heat. Only one of these eddy towers was operated at Site 2. The measurements at Site 2 are included in the analysis here to investigate whether there are systematic differences in momentum and heat fluxes across the field.

Selected setups included a measurements of the latent heat flux, either by closed-path infrared gas analyzer (IRGA, 
Table 1. Summary of the instrumentation deployed on the eddy flux towers during the Braunschweig experiment.

\begin{tabular}{|c|c|c|c|c|c|c|c|}
\hline Short name & Site & Height(s) [m] & $\begin{array}{l}\text { Logging/analysis } \\
\text { software }\end{array}$ & Ultrasonic anemometer & $\mathrm{H}_{2} \mathrm{O}$ sensor & Net radiation & Other parameters \\
\hline CEH 1 & 1 & 2.13 & CEH EC software & Gill Solent 1012RA & $\begin{array}{l}\text { IRGA (LiCor6262); } \\
\text { Kr Hygrometer (KH2O, } \\
\text { UV hygrometer; } \\
\text { Campbell Scientific } \\
\text { Inc.) }\end{array}$ & Rebs Q7 & $\begin{array}{l}\mathrm{CO}_{2} \text { flux, } T \text { gradient ( } 2 \\
\text { heights), } \mathrm{RH}, S_{t}, G \text {, soil } \\
T, e \text { gradient, } U \text { profile } \\
\text { ( } 5 \text { heights), wind direction } \\
\text { (wind vane), soil moisture, } \\
\text { rainfall, volumetric water } \\
\text { content }\end{array}$ \\
\hline CEH 2 & 2 & 2.13 & Edisol & Gill Solent 1012R & & & \\
\hline CEH-REA & 1 & 2.09 & $\begin{array}{l}\text { CEH REA/EC } \\
\text { software }\end{array}$ & Gill Solent 1012RA & & & \\
\hline DWD & near 1 & various & N/A & N/A & & N/A (different surface) & $\begin{array}{l}\mathrm{PAR}, T, \mathrm{RH}, U \text {, wind } \\
\text { direction, precipitation, } L_{d}\end{array}$ \\
\hline $\mathrm{ECN}$ & 1 & 2.0 & ECN software & Gill Solent 1012R & & & \\
\hline FAL-IUL & & 1.09 & FAL/IUL software & Gill HS & & & \\
\hline FRI & 1 & $2.15(2.00)$ & FRI software & Gill Solent 1012R & & Rebs Q7 & $\begin{array}{l}\text { Leaf wetness (clip sensors), } \\
\mathrm{O}_{3} \text { flux, } \mathrm{O}_{3} \text { concentration, } \\
S_{t}, G, \text { soil } T, T \text { gradient } \\
\text { ( } 2 \text { heights), } \mathrm{RH} \text { gradient, } U \\
\text { profile ( } 3 \text { heights) }\end{array}$ \\
\hline \multirow[t]{2}{*}{ INRA } & 1 & 2.04 & Edisol/INRA & Gill Solent 1012R & IRGA (LiCor6262) & $\mathrm{S} 1$ (Swissteco, $\mathrm{CH})$ & $\begin{array}{l}\mathrm{CO}_{2} \text { flux, leaf } \\
\text { temperatures, soil moisture, } \\
\text { PAR profile, } T \text { profile (xxx } \\
\text { heights) }\end{array}$ \\
\hline & & & software & & & & \\
\hline UMIST HS & 1 & 2.02 & UMIST software & Gill HS & Kr Hygrometer (KH20) & & $\mathrm{RH}, T$, total particle flux \\
\hline UMIST R2 & 1 & 2.86 & $\begin{array}{l}\text { CEH ASASP-x flux } \\
\text { software }\end{array}$ & Gill Solent 1012R & & & $\begin{array}{l}\text { Canopy } T \text { (radiative), size- } \\
\text { segregated particle flux }\end{array}$ \\
\hline
\end{tabular}

LI-COR Model 6262) or by Krypton hygrometer (KH20, Campbell Scientific). The CEH-1 IRGAs sampled through a $10 \mathrm{~m}$ long $1 / 4^{\prime \prime}$ OD Decabon ${ }^{\circledR}$ (polyethylene coated aluminium) tubing at a flowrate of $8 \mathrm{lpm}$ and the analogue signals of the calibrated output were recorded through the analogue inputs of the Gill Solent R1012A anemometer. The INRA IRGA sampled through a similar but shorter tube ( $1 \mathrm{~m}$, $10 \mathrm{lpm}$ ), recording the uncalibrated IRGA outputs through the analogue inputs of the INRA Gill Solent R1012. Unfortunately, the bit resolution of this setup was poor. Both IRGAs were calibrated approximately fortnightly with a dew point generator (LI-COR, LI-610).

Fluxes from the KH20 were calculated as

$\lambda E=\lambda \overline{q_{\mathrm{ref}}} \frac{\overline{w^{\prime} q_{K}^{\prime}}}{\overline{q_{K}}}$,

where $\lambda$ is the latent heat of evaporation, $q_{\mathrm{ref}}$ is the absolute humidity derived from a slow response $T / \mathrm{RH}$ sensor (in both system a Vaisala HUMITTER50 probe), and $q_{K}$ is the approximate absolute humidity measured by the KH20. This is calculated as

$q_{K}=\frac{\ln \left(V_{0}\right)-\ln (V)}{x K_{w}}$,

where $V_{0}$ is the KH20 output voltage for dry air, $V$ is the instantaneous output voltage, $x$ is the path length and $K_{w}$ is the effective extinction coefficient for water vapour. $V_{0}, x$ and
$K_{W}$ are manufacturer calibrated during annual calibrations. However, since $x$ and $K_{w}$ cancel in Eq. (20), this procedure does not rely on the absolute calibration of the instrument, which can change due to scaling of the windows, which were nevertheless cleaned daily with de-ionised water. Correction for oxygen or density fluctuations were not applied (Webb et al., 1980; van Dijk et al., 2003).

In addition to these EC measurements, momentum fluxes and sensible heat fluxes were also derived from two windspeed gradients (using cup anemometers) and three temperature profiles (using fine thermocouples). Sampling points were logarithmically spaced in height, which were adjusted after the cut of the grassland, and the number of sampling points is provided in Table 1. As these measurements rely on empirical parameterisations, they were excluded these from the consensus dataset. However, the results from these gradient measurements are compared against the EC to investigate the performance of the HAGM, which was used elsewhere to derive trace gas fluxes.

Several setups, including the nearby DWD station, included measurements of solar radiation $\left(S_{t}\right)$, photosynthetically active radiation (PAR) or net radiation $\left(R_{n}\right)$, as well as absolute temperature and relative humidity. It should be noted that several of the sonic anemometers formed part of relaxed eddy accumulation (REA) systems for $\mathrm{NH}_{3}$ (CEH REA; ECN and FAL-IUL) (Hensen et al., 2008). Although attempts were made to minimise the impact of these 
sampling systems on the anemometer measurements, they may nevertheless influence the measurements to some extent, especially during calm conditions.

All groups calculated averaged data every $15 \mathrm{~min}$, and clocks were synchronised to UTC (local time minus two hours). The comparatively short averaging period was chosen because it was felt that the high time-resolution would maximize the information on $\mathrm{NH}_{3}$ exchange processes. The frequency at which the spectral density functions peak increases linearly with measurement height. It was therefore estimated that the $15 \mathrm{~min}$ calculations at a height of about $2 \mathrm{~m}$ over the smooth grassland vegetation is at least comparable to an averaging time of $30 \mathrm{~min}$ over forest (e.g. Kaimal and Finnigan, 1994). This was further confirmed through the analysis of individual ogives of one of the setups which shows good levelling-out at the low frequency end.

Slow sensors such as the different components of the gradient systems were recorded on data loggers (Model 21X, Campbell Scientific), while all fast data were recorded on PCs. With the exception of INRA and CEH 2, who used the commercial logging and analysis software Edisol 2.0 (Moncrieff et al., 1997), all institutes applied there own logging and analysis code (listed in Table 1).

Three net radiometers were operated at Site 1 . The net radiometers were typically mounted at a height of $2 \mathrm{~m}$ and their footprint is therefore very different to that of the turbulent flux measurements.

Ground heat fluxes at the soil surface $(G)$ were derived with two semi-independent systems as part of the setups of $\mathrm{CEH}$ and FRI at Site 1. In both cases, soil heat fluxes were derived at a depth of $8 \mathrm{~cm}$, from duplicate measurements with heat flux plates (Campbell Scientific). To this was added the heat storage in the top $8 \mathrm{~cm}$, calculated from changes in soil temperature (averaged over measurements at 2 and $6 \mathrm{~cm}$ depth within each setup, by soil thermocouples, Campbell Scientific), continuous measurements of the soil water content at one single site (by INRA) and measurements of the bulk density (average of two independent measurements of 1.35 and $1.65 \mathrm{~g} \mathrm{~cm}^{-3}$ ).

Canopy temperature critically controls the potential for vegetation to react as a source of certain trace compounds. For example, isoprene emissions are known to be closely linked to leaf temperature. Similarly, ammonia emission potentials (compensation points) represent the gas phase concentration in equilibrium with the liquid phase $\mathrm{NH}_{4}^{+}$concentration and the $\mathrm{pH}$ in the leaf apoplast. This gas-phase concentration is therefore governed by the temperature dependence of the Henry and solubility equilibria and, at ambient temperature, approximately doubles every $5^{\circ} \mathrm{C}$ (Sutton et al., 2001). Thus for the correct parameterisation of the emission potential, an accurate estimate of the leaf surface temperature is paramount. We here compare three different ways of estimating leaf surface temperature:
1. A micrometeorological estimate of the average canopy temperature is calculated as the surface value of the temperature, following the big-leaf approach of Eq. (18).

2. An infrared radiation pyrometer (KT19.85, Heitronics $\mathrm{GmbH}$, Wiesbaden) and

3. fine thermocouple wires, mounted to the surface of leaves at different heights and senescence stages.

\subsection{Data analysis}

The first stage of data analysis was performed by the individual research groups and involved filtering of the 15-min flux data to remove periods of instrument calibration, instrument malfunction or power failure. The calculation procedures differed between the different groups, with different averaging methods and corrections, as summarized in Table 2 . These coarsely filtered data were then drawn together and subjected to the following filtering procedure: the exact position of each instrument mast in relation to the other masts, mobile laboratories and other obstructions to the fetch was determined and all flux data falling within obstructed sectors were removed from that individual dataset. Where more than one group measured an individual parameter, the median of each of wind direction $(d d), u_{*}, H$, and $\lambda E$ from the eddy covariance systems, together with $S_{t}, R_{n}$ and PAR were then calculated and carried forward in the analysis to allow the validity of each individual dataset to be assessed by comparison with the median data.

In the case of $d d$ this was performed by a simple inspection of the time-series plots to confirm that no gross alignment errors were evident. The assessment of the extent to which each individual dataset was representative of the "consensus" dataset (cf. Sect. 4.12), consisted of performing a least-squares linear regression of the individual dataset on the median dataset.

In addition, values of the estimated length of fetch available for the wind direction observed during each 15 min period, and the cumulative normalised footprint (CNF after Kormann and Meixner, 2001) function were calculated and included in the consensus dataset. Flags were also provided for each $15 \mathrm{~min}$ value to indicate whether the measurements were in any way compromised by field conditions, thus allowing individual groups to filter the data according to their specific needs. Specifically, unsuitable micrometeorological conditions were defined as occurring under any of the following conditions: $u(1 \mathrm{~m})<0.8 \mathrm{~m} \mathrm{~s}^{-1} ;-5 \mathrm{~m}<L<+5 \mathrm{~m}$; $\mathrm{CNF}<67 \%$ within the fetch. Non-stationarity flags were calculated following Dutaur et al. (1998) and Nemitz et al. (2002), by defining $I(t)$ such that:

$$
I(t)=\frac{1}{T} \int_{0}^{t} w^{\prime} \chi^{\prime} \cdot d \hat{t} ; \quad 0 \leq t \leq T .
$$


Table 2. Summary of the calculation procedures and corrections applied to the different measurements of the different groups.

\begin{tabular}{|c|c|c|c|c|c|c|c|c|c|c|c|c|c|c|c|c|c|c|c|c|c|}
\hline \multirow[t]{2}{*}{ Correction } & \multicolumn{3}{|c|}{ CEH1 } & \multicolumn{2}{|c|}{ CEH REA } & \multicolumn{2}{|c|}{$\mathrm{ECN}$} & \multicolumn{2}{|c|}{ FAL-CH } & \multicolumn{2}{|c|}{ FRI } & \multicolumn{3}{|c|}{ INRA } & \multicolumn{3}{|c|}{ UMIST HS } & \multicolumn{2}{|c|}{ UMIST R2 } & \multicolumn{2}{|c|}{$\mathrm{CEH} 2$} \\
\hline & $\tau$ & $H$ & $\lambda E$ & $\tau$ & $H$ & $\tau$ & $H$ & $\tau$ & $H$ & $\tau$ & $H$ & $\tau$ & $H$ & $\lambda E$ & $\tau$ & $H$ & $\lambda E$ & $\tau$ & $H$ & $\tau$ & $H$ \\
\hline 2-D rotation $(u=w=0)$ & $\checkmark$ & $\checkmark$ & $\checkmark$ & $\checkmark$ & $\checkmark$ & & & $\checkmark$ & $\checkmark$ & $\checkmark$ & $\checkmark$ & $\checkmark$ & $\checkmark$ & $\checkmark$ & $\checkmark$ & $\checkmark$ & $\checkmark$ & $\checkmark$ & $\checkmark$ & $\checkmark$ & $\checkmark$ \\
\hline 3-D rotation $(\operatorname{cov}(u v)=0)$ & & & & & & $\checkmark$ & $\checkmark$ & & & & & & & & & & & & & & \\
\hline Linear detrending & & & & & & & & $\checkmark$ & $\checkmark$ & & & & $\checkmark$ & & & & & & & & \\
\hline High-pass filter (McMillen) & & & & & & $\checkmark$ & $\checkmark$ & & & $\checkmark$ & $\checkmark$ & & & & & & & & & & \\
\hline Despiking & $\checkmark$ & $\checkmark$ & $\checkmark$ & $\checkmark$ & $\checkmark$ & & & $\checkmark$ & $\checkmark$ & $\checkmark$ & $\checkmark$ & $\checkmark$ & $\checkmark$ & $\checkmark$ & $\checkmark$ & $\checkmark$ & $\checkmark$ & $\checkmark$ & $\checkmark$ & $\checkmark$ & $\checkmark$ \\
\hline$H$ correction for humidity & & & & & & & & & & & $\checkmark$ & & $\checkmark$ & & & & & & & & \\
\hline (Schotanus et al., 1983; Liu et al., 2001) & & & & & & & & & & & & & & & & & & & & & \\
\hline Inlet frequency loss & & & & & & & & & & & & & & & & & & & & & \\
\hline Sensor separation & & & & & & & & & & & & & & & & & & & & & \\
\hline Density fluctuations (WPL correction) & & & & & & & & & & & & & & & & & & & & & \\
\hline$u_{*}=\operatorname{sqrt}(-\operatorname{cov}(\mathrm{uw}))$ & $\checkmark$ & & & $\checkmark$ & & $\checkmark$ & & & & & & & & & $\checkmark$ & & & $\checkmark$ & & $\checkmark$ & \\
\hline$u_{*}=\left(\operatorname{cov}(u w)^{2}+\operatorname{cov}(v w)^{2}\right)^{0.25}$ & & & & & & & & $\checkmark$ & & $\checkmark$ & & $\checkmark$ & & & & & & & & & \\
\hline
\end{tabular}

The value of $I(t)$ was regressed on $t$ for each averaging pe$\operatorname{riod}(T=15 \mathrm{~min})$ and the standard deviation of the regression line $\left(\sigma_{f}\right)$, used to calculate the relative stationarity coefficient $(\zeta)$ as

$\zeta=\frac{2 \sigma_{f}}{\overline{w^{\prime} \chi^{\prime}}}$

and periods of instationarity were defined as $\zeta>1.2$.

A consensus time-series of the zero plane displacement height $(d)$ was derived from comparison of eddy-covariance results with the profile measured with cup anemometers (Vector Instruments) at six heights. For periods of near neutral stability ( $\Psi_{M} \approx 0$ ) the value of $d$ in Eq. (8) was adjusted until the gradient estimate of $u_{*}$ matched the consensus value. This exercise was repeated for periods of varying $h_{c}$, to develop a relationship between $d$ and $h_{c}$, which was then used to derive a continuous time series of $d$ (shown in Fig. 10a).

\section{Results}

\subsection{Initial data reduction}

The first and second stages of data analysis (data filtering by institutes and filtering in relation to bad wind sectors) resulted in a reduction of the quantity of suitable flux data to between $52 \%$ and $82 \%$ at the individual measurement sites (Table 3). This reduction in data was a reflection principally of the degree of obstruction the individual masts experienced, rather than any inherent unreliability in individual systems.

In the following sections the different estimates are compared against a consensus dataset derived for Site 1. This was calculated as the average of those instruments that were deemed to provide equally reliable measurements for this site, as described in more detail below (Sect. 4.12).
Table 3. Statistics of initial data reduction.

\begin{tabular}{lcc}
\hline EC Tower & $\begin{array}{c}\text { Number of valid 15-min } \\
\text { mean data points }\end{array}$ & $\begin{array}{c}\text { \% valid } \\
\text { data }\end{array}$ \\
\hline CEH 1 & 1797 & 78 \\
CEH 2 & 1464 & 64 \\
CEH-REA & 1344 & 58 \\
ECN & 1637 & 71 \\
FAL-IUL & 1191 & 52 \\
FRI & 1419 & 62 \\
INRA & 1883 & 82 \\
UMIST HS & 1651 & 72 \\
UMIST R2 & 1533 & 67 \\
\hline
\end{tabular}

\subsection{Comparison of friction velocities}

The comparison of the analysis of friction velocity is presented in Fig. $2 \mathrm{a}-\mathrm{g}$. This indicates that with the exception of ECN (Fig. 2c), the average values of $u_{*}$ for each individual mast at Site 1 lay within $+7.6 \%$ and $-7.8 \%$ of the median value (as derived as the deviation of the slope from unity) an agreement judged to be very encouraging in view of the relatively large spatial distribution of masts in the field and the diverse nature of the anemometry, measurement height and eddy covariance software employed. Only the ECN system showed a somewhat larger underestimation of $-12.3 \%$, while the median standard deviation between measurements for each 15 min period lies at $13.9 \%$, averaged over the campaign, the standard deviation decreases to $2.1 \%$ (Table 4 ). This indicates that differences are mainly due to spatial and temporal fluctuations in the turbulence, rather than systematic differences

Although the ECN data showed a discrepancy of $-12.3 \%$ compared to the median, closer inspection of Fig. 2c shows that the least-squares regression was skewed by a relatively small number of scattered data points at low $u_{*}$ values and that the bulk of the data points lie along the 1:1 line. It was 

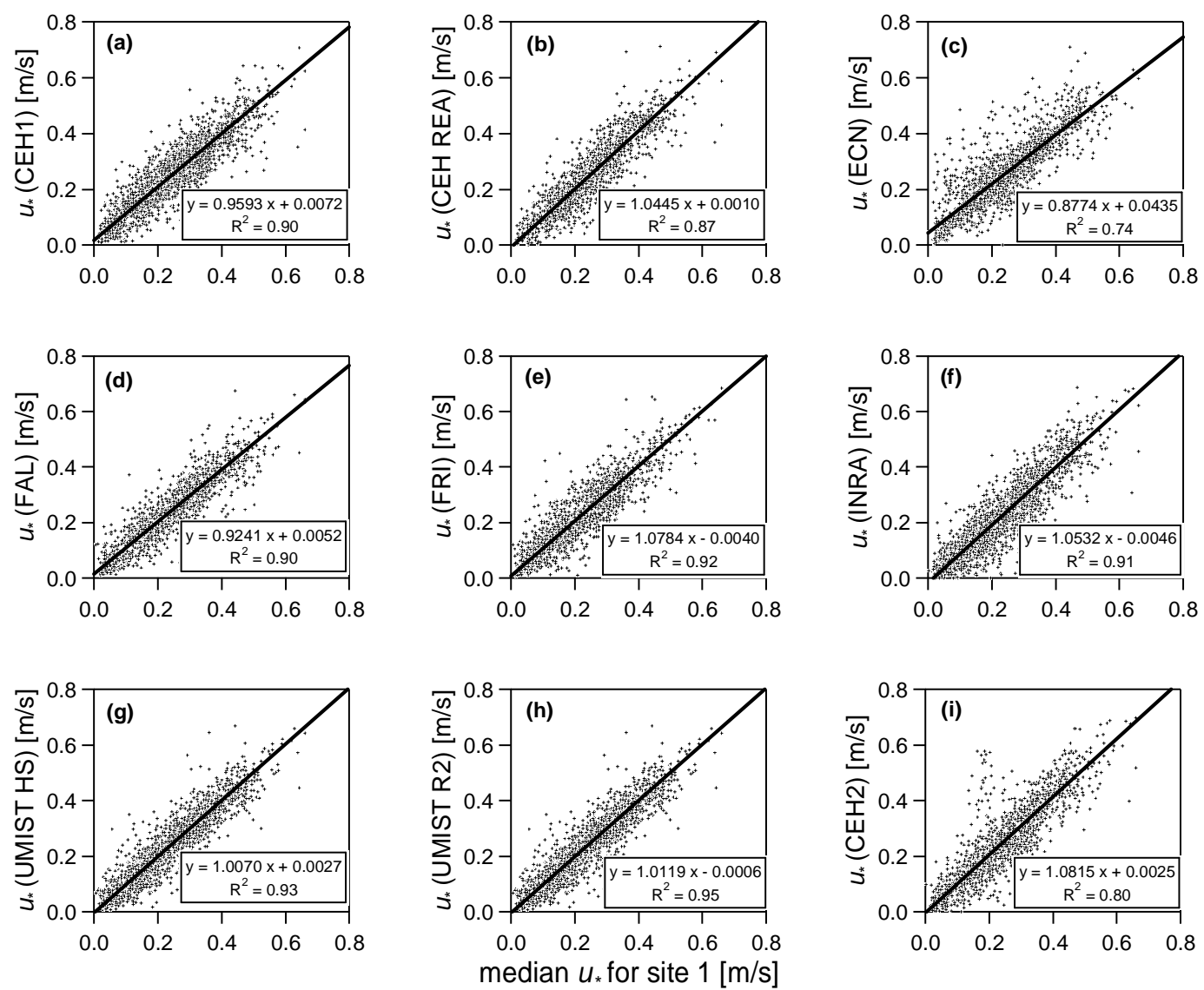

Fig. 2. Regression analysis of individual friction velocities as a function of median friction velocity.

therefore decided to retain the ECN data within the consensus dataset for $\tau$ and $u_{*}$. The ECN data were taken as part of the ECN REA system and its data acquisition was not optimized for eddy-covariance application. Thus, although the system calculated the parameters needed for the REA calculations online, over suitable averaging periods, eddycovariance results were stored every minute and had to be averaged in post-processing to provide 15 -min values. Here the covariance between the 1-min values could be accounted for. However, the 1-min co-variances had been rotated online on a 1-min basis and insufficient information was stored to undo this rotation. Thus, the ECN values may be subject to additional uncertainty.

The eddy covariance system at Site 2 (CEH EC2) (Fig. 2i) also produced values within $8 \%$ of the consensus dataset. The data were excluded from the consensus calculation for use of Site 1 measurements, on the basis that the spatial separation was in excess of $100 \mathrm{~m}$ and the mast was relatively close to the shelter belt at the eastern end of the field, although easterly winds were removed from the CEH EC2 dataset, when filtering for obstructed wind sectors. However, the good agreement suggests that the field was reasonably homogeneous as far as surface roughness and sensible heat exchange is concerned.
While $u_{*}$ is the parameter needed in the flux calculations, the more fundamental parameter is actually the momentum flux $(\tau)$, for which similar results were obtained (cf. Table 4).

\subsection{Comparison of sensible heat flux}

All sensible heat fluxes were calculated using the individual ultrasonic anemometers calculation of temperature based on the speed of sound in air. The results of the regression analysis are presented in Fig. 3a to $\mathrm{h}$ for Site 1, and in Fig. 3i for the single instrument at Site 2. For the majority of the instruments the discrepancy in the slope of the regression against the median value of $H$ lay in the range $+5.3 \%$ and $-6.9 \%$, while the intercept, was less than $2 \mathrm{~W} \mathrm{~m}^{-2}$, indicating how consistently the transition from unstable to stable conditions was measured. The exception to this rule were the ECN results, which again showed considerable scatter, for the reason described in the previous section. No systematic differences were found between different anemometer types. 

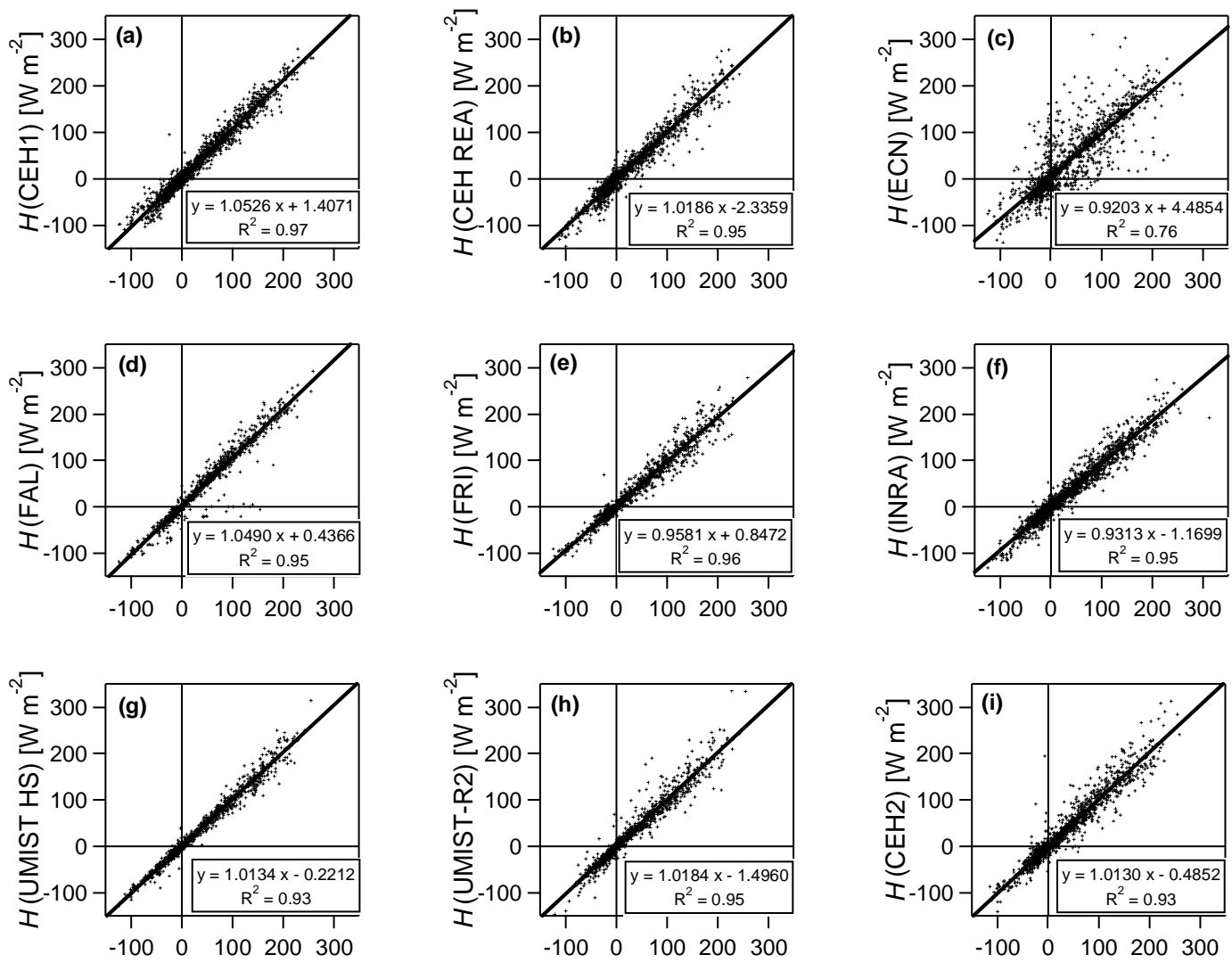

median $H$ for site $1\left[\mathrm{~W} \mathrm{~m}^{-2}\right]$

Fig. 3. Regression analysis of individual sensible heat fluxes as a function of median sensible heat flux.

Table 4. Summary of the statistics of the measurements with the different setups.

\begin{tabular}{lcrrr}
\hline & $\begin{array}{c}\text { No of } \\
\text { estimates }\end{array}$ & Mean Stdev & $\begin{array}{r}\text { Median Rel. } \\
\text { Stdev [\%] }\end{array}$ & $\begin{array}{r}\text { Rel stdev of } \\
\text { campaign } \\
\text { averages [\%] }\end{array}$ \\
\hline Momentum flux $(\tau)$ & 8 & $0.022 \mathrm{~N} \mathrm{~m}^{-2}$ & 27.3 & 2.5 \\
Friction velocity $\left(u_{*}\right)$ & 8 & $0.039 \mathrm{~m} \mathrm{~s}^{-1}$ & 13.9 & 2.1 \\
Sensible heat flux $(H)$ & 8 & $14.3 \mathrm{~W} \mathrm{~m}^{-2}$ & 57.7 & 8.3 \\
Latent heat flux $(\lambda E)$ & 4 & $20.6 \mathrm{~W} \mathrm{~m}^{-2}$ & 25.1 & 17.8 \\
Net radiation $\left(R_{n}\right)$ & 3 & $6.6 \mathrm{~W} \mathrm{~m}^{-2}$ & 3.8 & 6.0 \\
Solar radiation $\left(S_{t}\right)$ & 3 & $10.3 \mathrm{~W} \mathrm{~m}^{-2}$ & 5.0 & 1.7 \\
\hline
\end{tabular}

* Averages were calculated only over those periods where all measurement systems were providing data.

\subsection{Comparison of aerodynamic gradient technique and eddy-covariance}

Friction velocities and sensible heat flux were also calculated from the two gradient systems for wind speed and three temperature profiles, using the hybrid aerodynamic gradient approach. Stability corrections were based on $L$ derived from the median eddy-covariance results, while heat fluxes were calculated by combining the stability corrected temperature profiles with the median $u_{*}$ of the eddy-covariance measurements. This approach mimics the calculation of gradient trace gas fluxes in the companion papers and provides a direct test of this approach. The gradient values show more scatter against the median eddy-covariance values than the individual eddy-covariance measurements (Fig. 4), with smaller correlation coefficients. Both $u_{*}$ and $H$ tend to show some excursions towards larger values where the gradient approach appears to overestimate the fluxes and it is mainly 

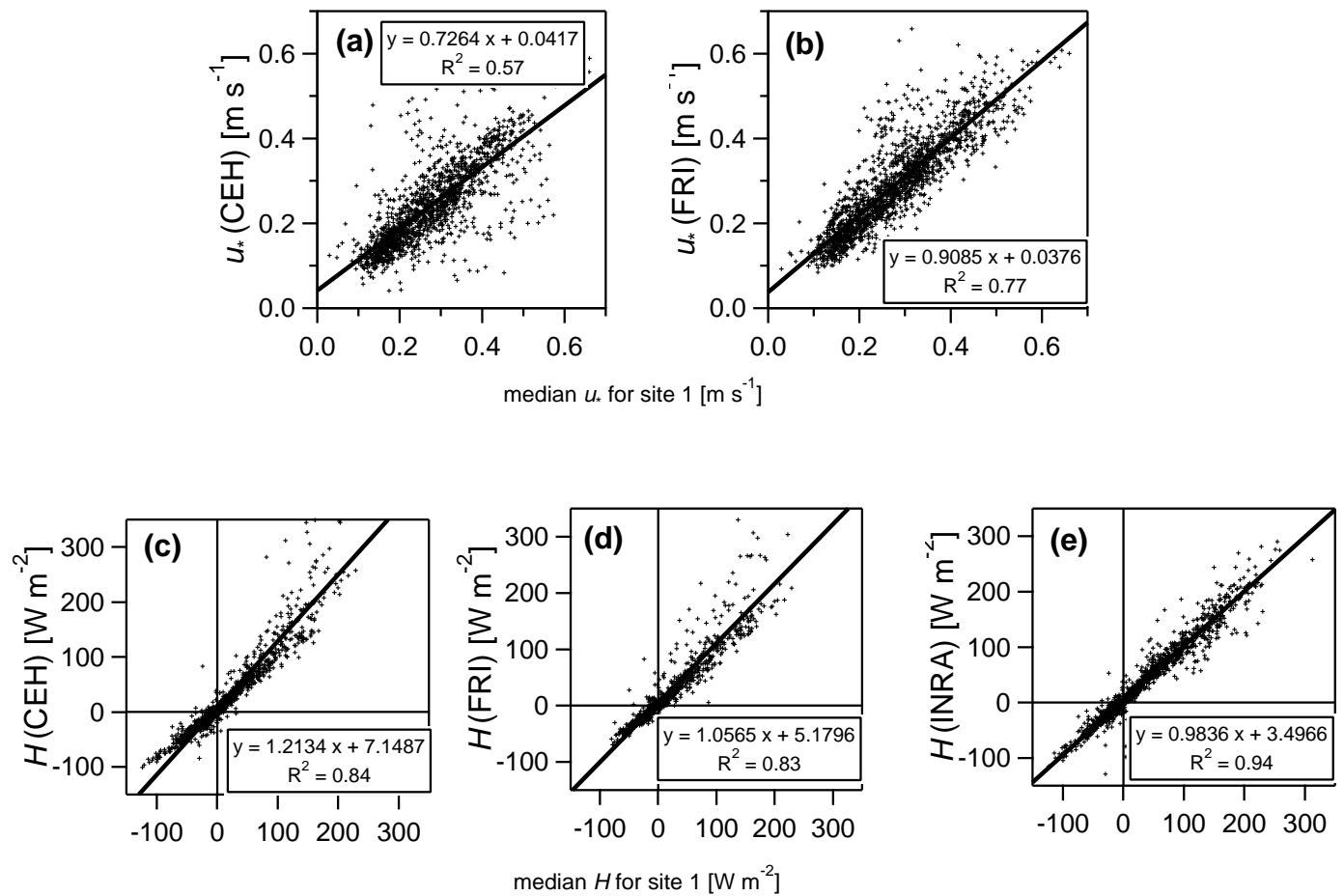

Fig. 4. Regression analysis of friction velocity $\left(u_{*}\right)$ and sensible heat flux $(H)$ derived from gradient measurements using the hybrid aerodynamic gradient technique, against median eddy-covariance results.

these points that are responsible for slopes larger than unity on the regressions for $H$. In addition, under stable conditions, $H$ from the gradient approach appears to be suppressed compared with the EC estimate, which indicates that the stability correction of Webb (1970) used here for unstable conditions may over-correct under these conditions.

\subsection{Latent heat flux}

Latent heat fluxes were measured solely at Site 1 using two open-path sensors of CEH and UMIST (Fig. 5a and c) and two closed-path sensors of INRA and CEH (Fig. 5b and d). Details of the different instruments used are summarized in Table 1.

Agreement between the four instruments for latent heat flux was poorer than that for sensible heat or momentum flux, with the CEH open- and closed-path instruments (Fig. 5a and c) providing similar medium estimates, the INRA system a lower and the UMIST system an upper bound. Possible reasons are discussed below (Sect. 5.3).

\subsection{Net radiation}

During the GRAMINAE integrated experiment at Braunschweig, fluxes of ammonia and other trace gases were either calculated by eddy-covariance (fluxes of latent and sensible heat, momentum, ozone, particles), hybrid aerodynamic gradient techniques $\left(\mathrm{NH}_{3}\right.$, acid gases) or relaxed eddy accumulation $\left(\mathrm{NH}_{3}\right)$. Hence, net radiation $\left(R_{n}\right)$ was not needed for
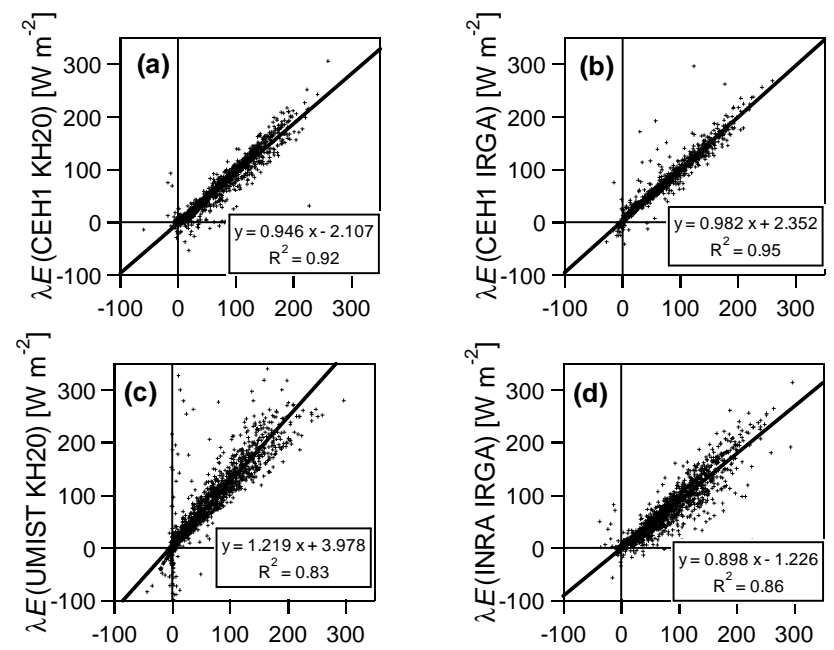

median $\lambda E$ for site $1\left[\mathrm{~W} \mathrm{~m}^{-2}\right]$

Fig. 5. Regression analysis of individual latent heat fluxes as a function of median latent heat flux.

the flux calculations per se as it would be the case in Bowen ratio technique. However, the accuracy with which $R_{n}$ can be measured is important for the interpretation of the energy balance closure at this site. In addition, $R_{n}$ was needed to drive some of the numerical models, which incorporated their own heat balance calculation (Personne et al., 2009). 

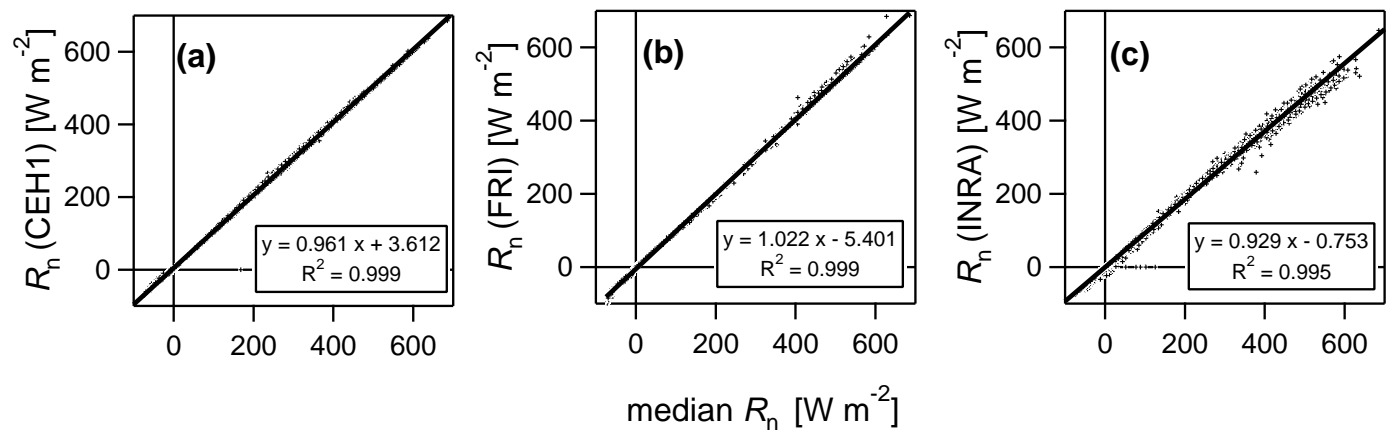

Fig. 6. Regression analysis of individual measurements of net radiation $\left(R_{n}\right)$ a function of the median value of $R_{n}$.
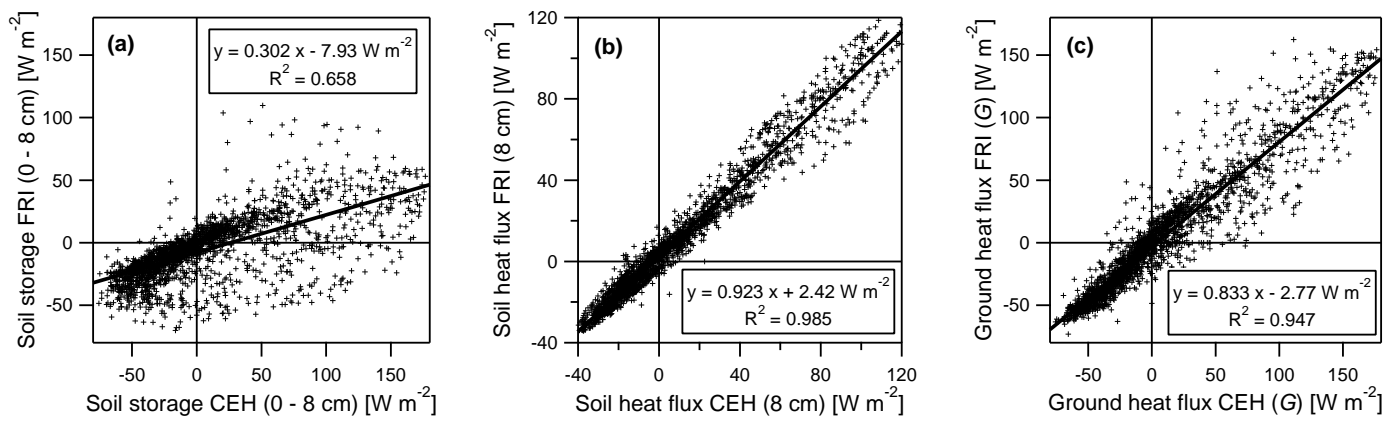

Fig. 7. Regression analysis of the two measurements of ground heat flux $(G)$ and its two components, the soil heat flux at $8 \mathrm{~cm}$ depth and the heat storage within the top $8 \mathrm{~cm}$ of the ground.

The CEH and FRI radiometers in particular showed a very tight relationship, while the INRA instrument shows some more variability.

\subsection{Ground heat flux}

The scatter in the comparison between the estimates of the ground heat flux $(G)$ of the two different systems deployed (Fig. 7a) is dominated by the disagreement at times in the soil heat storage (Fig. 7c), while the soil heat fluxes agreed closely (Fig. 7b).

\subsection{Closure of the energy balance and flux corrections}

The closure in the energy balance at the site is a common test to assess potential losses in the turbulent fluxes (Barr et al., 2006; Hammerle et al., 2007). In the ideal case, the net radiation (balance of up- and down-ward short and long-wave components) should balance the sum of heat flux into the soil at the soil surface $(G)$, and the turbulent fluxes of sensible heat $(H)$ and latent heat $(\lambda E)$. The regression of the sum of $H+\lambda E$ against $R_{n}-G$ shows a slope of 0.796 , with an intercept of $-10.04 \mathrm{~W} \mathrm{~m}^{-2}$ and an $R^{2}$ of 0.98 (not shown). Thus, with the consensus dataset approximately $80 \%$ energy balance closure is achieved, with an average residual (bold solid line in Fig. 8a) of about $+60 \mathrm{~W} \mathrm{~m}^{-2}$ during the day and $+8 \mathrm{~W} \mathrm{~m}^{-2}$ at night. Not all groups applied all corrections that apply to their respective instruments. Figure $8 \mathrm{~b}$ explores the average magnitude of the different corrections, which have been applied to some, but not all measurements as detailed in Table 2. The correction of the latent heat flux measured by KH20 for cross sensitivity to oxygen (van Dijk et al., 2003) and the Webb-Pearman-Leuning (WPL) correction of the latent heat flux due to density fluctuations caused by the latent heat flux (WPL $\lambda E$ ) (Webb et al., 1980), both applicable to the $\lambda E$ measurement by Krypton hygrometer, are small. More important are the Schotanus correction of the sensible heat flux for effects of humidity fluctuations on the speed of sound (Schotanus et al., 1983), and the WPL correction for the sensible heat flux (WPL $H$ ) again applicable for the $\mathrm{KH} 20 \lambda E$ measurement. Largest, however, is the correction for the flux loss due to damping in the inlet of the infra-red gas analyzer (estimated from Horst, 1997 based on the CEH1 setup). The sum of all corrections (solid bold line in Fig. 8b) adds up to $+35 \mathrm{~W} \mathrm{~m}^{-2}$ during the day and $-13 \mathrm{~W} \mathrm{~m}^{-2}$ at night. The corrections may be weighted according to the number of instrument that went into the calculation of the average $\lambda E$ and $H$ which did not have the respective correction applied, and it then amounts to $+18 \mathrm{~W} \mathrm{~m}^{-} 2$ during the day and $-5 \mathrm{~W} \mathrm{~m}^{-2}$ at night. Application of this weighted correction decreases the residual of the energy balance by about a quarter (dotted bold line in Fig. 8a). 

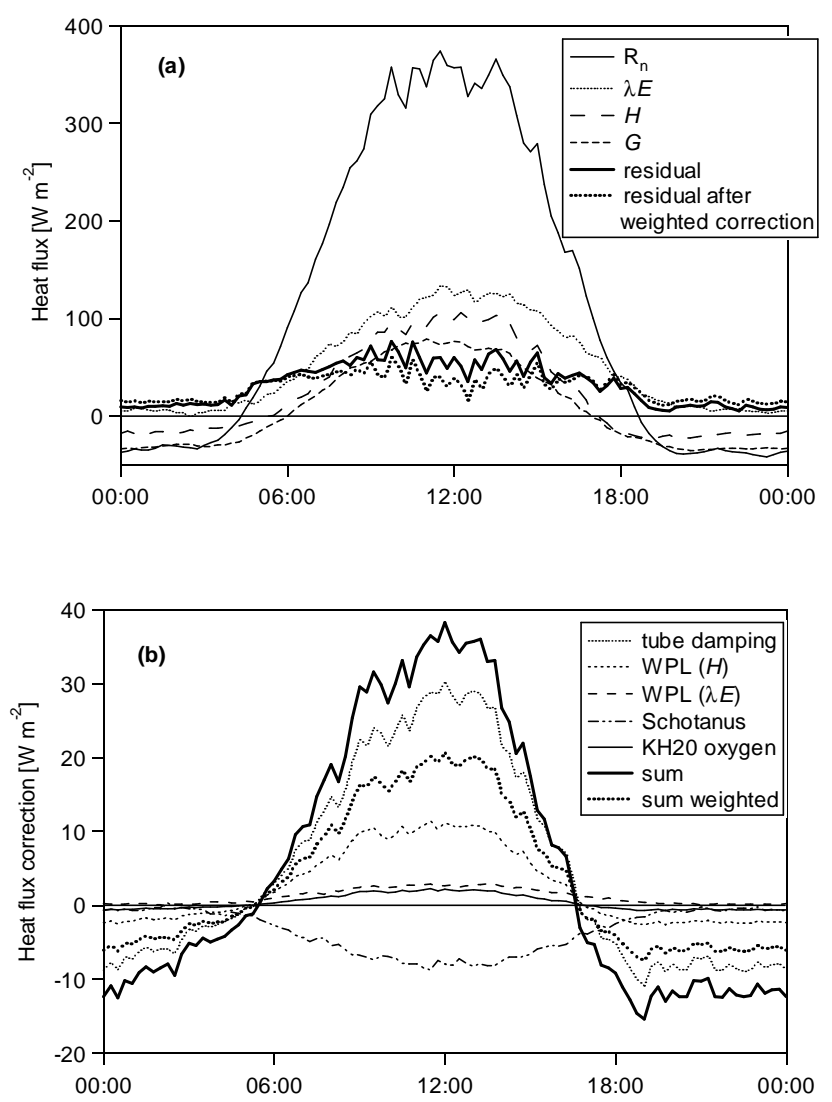

Fig. 8. (a) Average diurnal cycle of the heat flux components: net radiation $\left(R_{n}\right)$, latent heat flux $(\lambda E)$, sensible heat flux $(H)$, ground heat flux $(G)$ and the residual between $R_{n}$ and the sum of the other components before and after weighted correction has been applied. (b) Average diurnal cycles of the flux corrections for tube damping (based on CEH $\lambda E$ measurement by IRGA), Webb-PearmanLeuning correction for density fluctuations associated with $H$ and $\lambda E$ (applicable to $\lambda E$ measurements by $\mathrm{KH} 20$ ), the Schotanus correction of sensible heat flux for sensitivity of speed-of-sound to humidity fluctuations and correction of the KH20 latent heat flux for cross-sensitivity to oxygen. Also shown are the sum of the correction (bold solid line) and the sum weighted according to the number of instruments that went into the calculation of the residual and did not have the appropriate correction applied (bold dotted line).

\subsection{Solar radiation and PAR}

Solar radiation $\left(S_{t}\right)$ or PAR is needed to parameterise the stomatal resistance needed for SVAT modelling. The comparison of the three measurements of $S_{t}$ (by CEH, FRI and DWD) was very encouraging. CEH and FRI estimates were on average within $3 \%$ of each other, with the DWD estimate showing good agreement overall, but a larger amount of scatter. This was probably due to the spatial separation reflecting changes in cloudiness at the averaging scale of $15 \mathrm{~min}$. The INRA PAR sensor derived a quantum flux which was $22 \%$ higher than that measured by DWD. Hence it was decided to use the more robust estimates of $S_{t}$ for parameterisations.
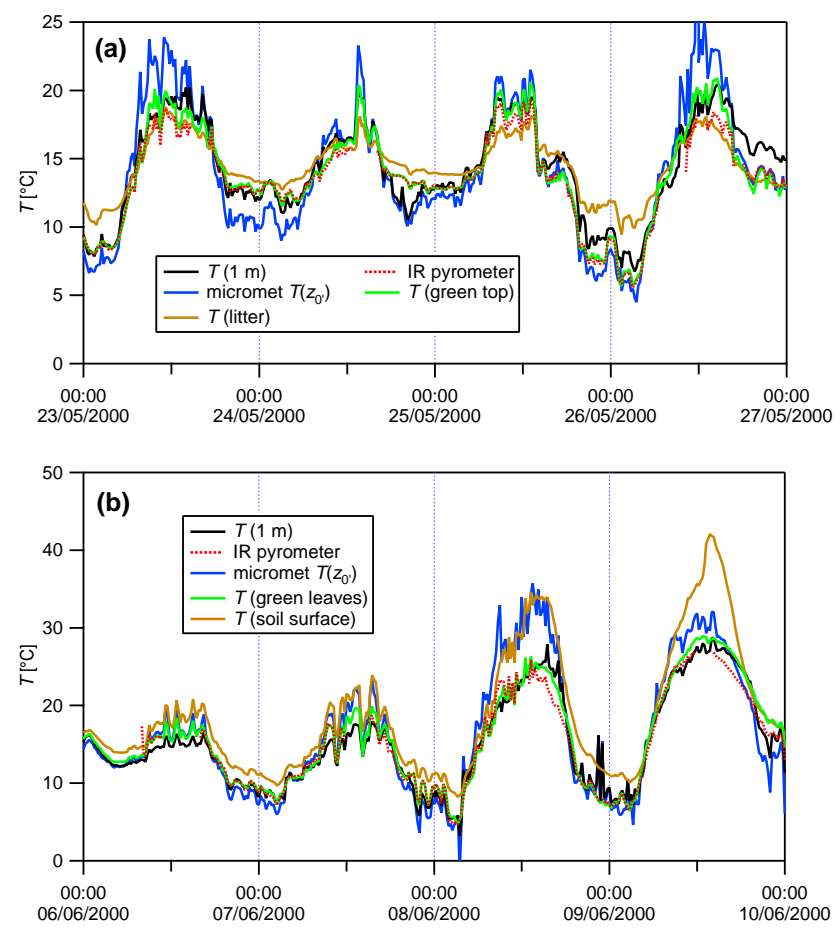

Fig. 9. Comparison between different estimates of canopy temperature, comparing a pyrometer, a bulk value derived from the micrometeorological parameters and measurements by thermo couple on a range of leaf types. (a) before the cut, grass height $0.75 \mathrm{~m}$; (b) after the cut, grass height 0.20 to $0.26 \mathrm{~m}$.

\subsection{Comparison of canopy temperature estimates}

The intercomparison of the different measures of canopy temperature are presented in Fig. 9 alongside the best estimate of the air temperature at $z-d=1 \mathrm{~m}$. The graph contrasts two four day example periods before and after the cut of the grassland from $0.75 \mathrm{~m}$, between which the position of the thermocouples was necessarily changed.

Before the cut the vertical profile of the temperature of the green leaves is linked to light interception and the measured temperature profile in the canopy air space (not shown). The pyrometer measurement closely follows the temperature of the green top leaves of the canopy. By contrast, the micromet estimate of $T\left(z_{0}^{\prime}\right)$ is more closely related to the temperature of the lower leaves in the canopy (where the bulk of the biomass is located) (Herrmann et al., 2009). This estimate also shows the largest diurnal range and values which appear to be lower or higher than the temperature of any physical element measured by the thermocouples.

After the cut, all leaves were exposed to the incoming radiation and here the colour (reflectance) and ability for evapotranspiration appear to account for the large difference of the physical temperature between green leaves as well as yellow/brown and senescent leaves of typically $10 \mathrm{~K}$ on warm days. While the pyrometer measurement reflects the 


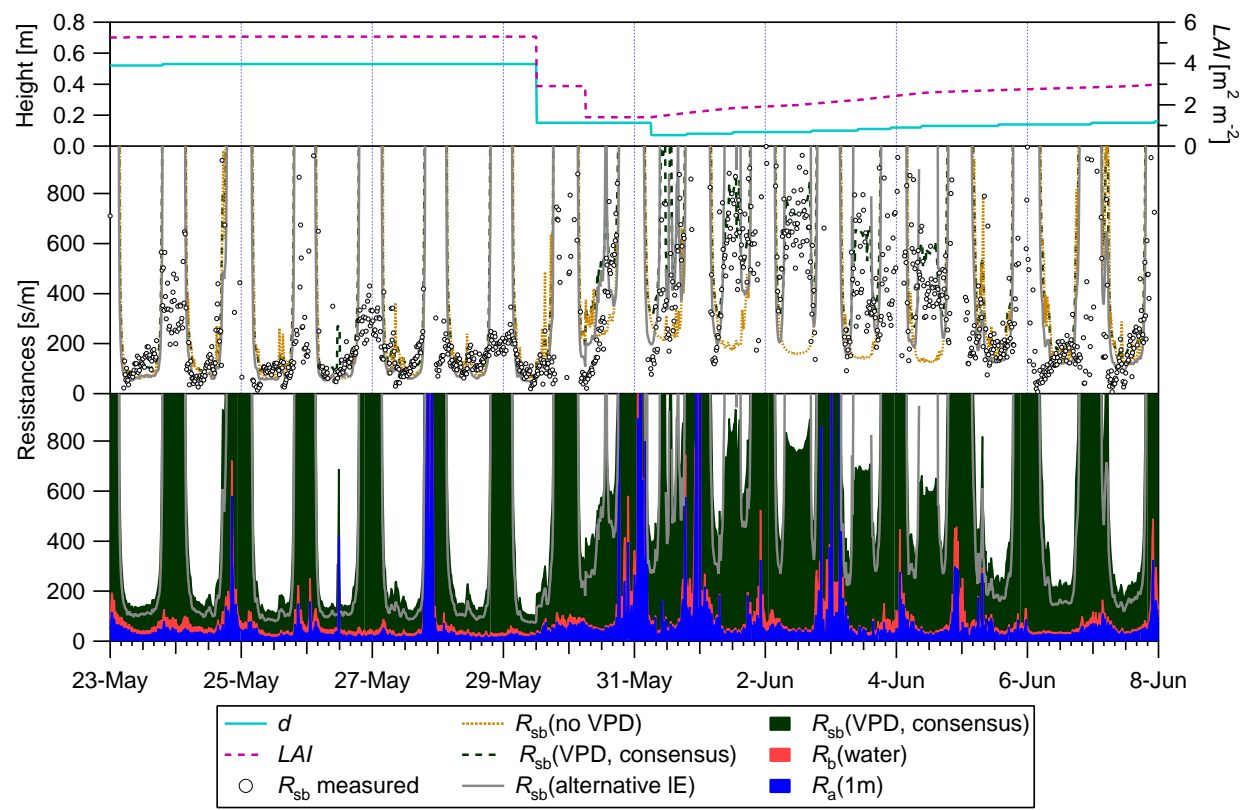

Fig. 10. (a) Time-series of zero-plane displacement height $(d)$ and leaf area index (LAI). (b) Parameterisation(s) of $R_{s} b$ in relation to measurement derived values. (c) Breakdown of consensus total resistance into aerodynamic $\left(R_{a}\right)$, laminar-sublayer resistance $\left(R_{b}\right)$ and bulk stomatal resistance $\left(R_{s b}\right)$.

temperature of the green leaves only, the micrometeorological estimate is heavily influenced by the dry vegetation.

\subsection{Estimates of bulk stomatal resistance}

The bulk stomatal resistance $\left(R_{s b}\right)$ may be calculated from $\lambda E$ according to Eq. (17), during periods when (a) $\lambda E$ is dominated by evapotranspiration (leaf surfaces dry) and (b) the extrapolation of $T$ and $e$ to derive the surface values $\left(T\left(z_{0}^{\prime}\right)\right.$ and $\left.e\left(z_{0}^{\prime}\right)\right)$ is reasonably robust $\left(R_{a}+R_{b}\right.$ small, i.e. windy conditions). Former parameterisations (e.g. Jarvis, 1976) have shown $R_{s b}$ to vary with LAI, PAR (closely related to $S_{t}$ ), leaf water potential and relative humidity (or water vapour pressure deficity, VPD). Light availability is clearly the main driver for stomatal functioning. However, prolonged dry and warm periods during the Braunschweig experiment meant that drought stress also had to be taken into account, together with changes in LAI during the management of the grassland. While LAI was measured only sporadically throughout the campaign, canopy height $\left(h_{c}\right)$ was continuously monitored. Hence, a relationship between LAI and $h_{c}$ was derived which allowed a continuous time series of LAI to be constructed (Fig. 10a):

$$
\mathrm{LAI}=1.8899 \times \ln \left(h_{c}\right)+5.8483
$$

where LAI is in $\mathrm{m}^{2} \mathrm{~m}^{-2}$ and $h_{c}$ is in $\mathrm{m}$. The measurement derived estimate of $R_{s b}$ is shown as circles in Fig. 10b. It clearly responds to the cut of the grass on 29 May. Although a parameterisation that ignores the water status (parameterised through VPD) can reproduce the measurement derived values of $R_{s b}$ well on many days (Fig. 10b), it tends to underestimate the $R_{s b}$ on hot, dry days (e.g. 31 May-4 June). Inclusion of VPD into a parameterisation, based on the consensus data, leads to a much improved fit to the measurement derived values (based on Jarvis, 1976):

$$
\begin{aligned}
R_{s b}= & R_{s b, \min }\left(1+\frac{b}{\max (0.01, S t)}\right) \frac{\mathrm{LAI}_{\mathrm{ref}}}{\mathrm{LAI}} \\
& \left(1-b_{e} \times \min (\mathrm{VPD}, 2.5)\right)^{-1}
\end{aligned}
$$

Here $R_{s b}$ is in s m${ }^{-1}, S_{t}$ is in $\mathrm{W} \mathrm{m}^{-2}$ and VPD is in $\mathrm{kPa}$. The fit parameters are $R_{s b, \min }=50 \mathrm{~s} \mathrm{~m}^{-1}, \mathrm{LAI}_{\mathrm{ref}}=5.18$, $b=200 \mathrm{~m}^{2} \mathrm{~W}^{-1}$ and $b_{e}=0.31 \mathrm{kPa}^{-1}$. As discussed in Sect. 5.3 below, it is possible that $\lambda E$ was underestimated in the consensus dataset for a number of reasons. Since UMIST $\lambda E$ results in an improved energy budget closure, an alternative parameterisation of $R_{s b}$ was derived to fit the UMIST data, resulting in modified parameters of $R_{s b, \min }=30 \mathrm{~s} \mathrm{~m}^{-1}$ and $b_{e}=0.4 \mathrm{kPa}^{-1}$. The resulting resistances are typically $40 \mathrm{~s} \mathrm{~m}^{-1}$ smaller during daytime, which is similar to the contribution of $R_{a}+R_{b}$ (Fig. 10c).

\subsection{Generation of a consensus dataset}

One of the reasons for the detailed intercomparison of the micrometeorological measurements was to produce a single, consensus dataset which all participants could use for further analysis of their individual measurements, such as the calculation of gas and particle fluxes and the parameterisations 
of models to reproduce the exchange. The measurements summarised in the consensus dataset were based on a $15 \mathrm{~min}$ mean for Site 1 and are summarised in Table 5.

\section{Discussion}

\subsection{Sources of discrepancy in the estimates}

Comparisons between eddy-covariance measurements have been presented in the literature before, albeit with different motivations and foci (Dyer et al., 1982; Tsvang et al., 1985; Fritschen et al., 1992; Christen et al., 2000; Mauder and Foken, 2001; Wieser et al., 2001; Mauder et al., 2008). In these studies an attempt was generally made either to study turbulence structures (using identical instrumentation and analysis approaches), to compare anemometers and latent heat flux instrumentation (using identical analysis packages) or to compare analysis approaches (using the same input data). By contrast, this study deliberately compares the measurement results achieved by independent groups using their own instrumentation and analysis techniques, to assess typical uncertainties that would be expected by these differences.

Disagreement between individual sensors may generally be due to: (i) intrinsic differences in the instrumentation and sensor response times; (ii) differences in the mounting (e.g. potential interferences from gas inlets, REA; difference in turbulence scales at different heights); (iii) landscape heterogeneity (due to horizontal inhomogeneities and/or different footprint sizes associated with different measurement heights); (iv) statistical variations and (v) differences in the analysis procedures. The relative contribution of these factors is in general difficult to quantify. However, the analysis presented here provides strong evidence for the main factors causing differences in the measurements of the individual parameters: the momentum fluxes (and the associated parameter $u_{*}$ ) shows significant variation between anemometers for each 15-min period, especially at low windspeeds. Averaged over the whole campaign, however, the different estimates are very close indeed, with a standard deviation of $<1 \%$, indicating that no biases are introduced by the instrumentation or the analysis techniques applied. Thus it is likely that the uncertainty in the momentum flux is dominated by stochastic spatial and temporal variability in the turbulence (which are conceptually similar, if Taylor's hypothesis is fulfilled). These findings are consistent with the study of Dämmgen et al. (2005), who operated an array of identical sonic anemometers, analysed with the same technique, to assess the averaging time required for the results to converge. As a consequence turbulence parameters derived as an average over several anemometers provide much improved inputs into inferential models (such as SVAT models) or gradient flux calculations than would be derived with a single setup.
In contrast to $u_{*}$ (and thus $\tau$, not shown), the standard deviation of $H$ for each 15-min averaging period $\left(14.3 \mathrm{~W} \mathrm{~m}^{-2}\right)$ shows similar variability as the campaign averages $\left(10.8 \mathrm{~W} \mathrm{~m}^{-2}\right)$ (cf. Table 4$)$. This indicates that there are systematic differences between anemometers or that analysis approaches differ more for heat fluxes. The sensible heat flux is derived from the speed of sound, averaged over the same volume as the momentum flux and, presumably, calculated with similar numerical routines as $\tau$. Hence, the reason for the small systematic differences is not immediately obvious. The way temperature is calculated from the speed of sound differs between anemometers. The Gill R1012 is known to have difficulties in measuring the speed of sound reliably at high windspeeds, as this is derived from only one transducer pair, whose distance may vary when the anemometer cage flexes under high windspeeds. This has been improved in the more recent models (such as the Gill HS) where all transducer pairs enter the calculation and distortions of the anemometer cage will lead to compensating effects on the different transducers. Also, these newer anemometers can now directly calculate the speed-of-sound temperature in the hardware, while this calculation has to be performed off-line in the software for the R1012. Indeed, most of the data from the HS sonic anemometers of FAL and UMIST fall somewhat more closely onto the regression line (Fig. 3d and g), which was also observed in other studies (e.g. Christen et al., 2000 ), while the overall $R^{2}$ is similar to other anemometers, due to the effect of some outliers. Not all groups have applied the latent heat flux correction for the measurement of $H$ according to Schotanus et al. (1983), as latent heat fluxes were only measured as part of four of the nine setups. The average magnitude of these corrections is illustrated in Fig. 8b. However, assessment of the biases between institutes (Fig. 3) does not reveal a consistent relationship with anemometer model or latent heat flux correction.

In addition, some groups perform a high-pass filtering procedure on the raw data (e.g. McMillen, 1988), to remove low frequency noise, some apply linear detrending, while others have assumed that low frequency variations contribute to the vertical turbulent flux (Table 2). The different views can all be supported by the literature (Finnigan et al., 2003, and references therein). The filters will tend to result in on average smaller fluxes and the effect of this filter could indeed be larger on $H$ than on $\tau$.

In a study, where data from two different anemometer types were processed with a common analysis program, Mauder et al. (2006) found that sensible heat fluxes compared within $5 \%$ and $10 \mathrm{~W} \mathrm{~m}^{-2}$, which is about half the uncertainty found here, using a range of analysis programs and anemometers. They also report an uncertainty of $15 \%$ or less than $30 \mathrm{~W} \mathrm{~m}^{-2}$ in their latent heat flux estimates. Mauder et al. (2007) compared the performance of different analysis packages/methodologies applied to the same data and concluded that methodological differences resulted in deviations of $10 \%$ and $15 \%$ for sensible and latent heat fluxes, 
Table 5. Summary of data present in the consensus dataset.

\begin{tabular}{|c|c|c|c|}
\hline Symbol & Description & Units & Derived from \\
\hline$d d$ & Wind direction & $\begin{array}{l}\text { degrees } \\
\text { (magnetic) }\end{array}$ & CEH EC1, CEH REA 1, ECN, INRA1, UMIST HS, UMIST R2, FRI1 \\
\hline$u_{*}$ & Friction velocity & $\begin{array}{l}\text { from north } \\
\mathrm{m} \mathrm{s}^{-1}\end{array}$ & CEH EC1, CEH REA 1, ECN, INRA1, UMIST HS, UMIST R2, FRI1 \\
\hline$H$ & Sensible heat flux & $\mathrm{W} \mathrm{m}^{-2}$ & CEH EC1, CEH REA 1, ECN, INRA1, UMIST HS, UMIST R2, FRI1 \\
\hline$\lambda E$ & Latent heat flux & $\mathrm{W} \mathrm{m}^{-2}$ & CEH EC 1 (IRGA), CEH EC 1 (KH20), INRA1 (IRGA), UMIST HS (KH20) \\
\hline$R_{n}$ & Net radiation & $\mathrm{W} \mathrm{m}^{-2}$ & CEH1 BR, FRI1 \\
\hline$G$ & Soil Heat Flux & $\mathrm{W} \mathrm{m}^{-2}$ & CEH1 BR, FRI1 \\
\hline$S_{t}$ & Incident Solar Radiation & $\mathrm{Wm}^{-2}$ & CEH1 BR, FRI1, DWD \\
\hline PAR & $\begin{array}{l}\text { Photosynthetically active } \\
\text { radiation }\end{array}$ & $\mu \mathrm{mol} \mathrm{m}^{-2} \mathrm{~s}^{-1}$ & ${ }^{1}$ INRA1, DWD \\
\hline$d$ & $\begin{array}{l}\text { Zero-plane displacement } \\
\text { height }\end{array}$ & $\mathrm{m}$ & $\begin{array}{l}\text { derived from wind profile and consensus } u_{*} \\
\text { and measured } h_{c} \text { at Site } 1\end{array}$ \\
\hline$h_{c}$ & canopy height & $\mathrm{m}$ & interpolated from daily measurements \\
\hline$u(1 \mathrm{~m})$ & Wind speed at $\mathrm{z}-\mathrm{d}=1 \mathrm{~m}$ & $\mathrm{~ms}^{-1}$ & CEH EC1, CEH REA 1, ECN, INRA1, UMIST CPC1, UMIST R2, FRI1 \\
\hline$L$ & $\begin{array}{l}\text { Monin-Obukhov stability } \\
\text { length }\end{array}$ & $\mathrm{m}$ & derived from $u_{*}, H, T$ ( $1 \mathrm{~m}$ approx $)$ \\
\hline$z_{0}$ & Surface roughness length & $\mathrm{mm}$ & derived from $u_{*}, u(1 \mathrm{~m})$ and $L$ \\
\hline $\begin{array}{l}R_{a} \\
(1 \mathrm{~m})\end{array}$ & Aerodynamic resistance & $\mathrm{s} \mathrm{m}^{-1}$ & derived from $L, u_{*}, u$ \\
\hline$R_{b} \mathrm{NH}_{3}$ & $\begin{array}{l}\text { Sub-layer resistance } \\
\text { for } \mathrm{NH}_{3}\end{array}$ & $\mathrm{sm}^{-1}$ & derived from $z_{0}, u_{*}, T$ ( $1 \mathrm{~m}$ approx $)$ \\
\hline$R_{b} \mathrm{SO}_{2}$ & $\begin{array}{l}\text { Sub-layer resistance } \\
\text { for } \mathrm{SO}_{2}\end{array}$ & $\mathrm{~s} \mathrm{~m}^{-1}$ & derived from $z_{0}, u_{*}, T$ ( $1 \mathrm{~m}$ approx $)$ \\
\hline$R_{b} \mathrm{CO}_{2}$ & $\begin{array}{l}\text { Sub-layer resistance } \\
\text { for } \mathrm{CO}_{2}\end{array}$ & $\mathrm{~s} \mathrm{~m}^{-1}$ & derived from $z_{0}, u_{*}, T$ ( $1 \mathrm{~m}$ approx $)$ \\
\hline$R_{b} \mathrm{H}_{2} \mathrm{O}$ & $\begin{array}{l}\text { Sub-layer resistance } \\
\text { for } \mathrm{H}_{2} \mathrm{O}\end{array}$ & $\mathrm{s} \mathrm{m}^{-1}$ & derived from $z_{0}, u_{*}, T$ ( $1 \mathrm{~m}$ approx $)$ \\
\hline$R_{b} \mathrm{O}_{3}$ & $\begin{array}{l}\text { Sub-layer resistance } \\
\text { for } \mathrm{O}_{3}\end{array}$ & $\mathrm{~s} \mathrm{~m}^{-1}$ & derived from $z_{0}, u_{*}, T$ ( $1 \mathrm{~m}$ approx $)$ \\
\hline$T(1 \mathrm{~m})$ & Temperature at $z-d=1 \mathrm{~m}$ & ${ }^{\circ} \mathrm{C}$ & CEH1 BR, INRA1, UMI1 CPC, FRI1 BR, ... \\
\hline$e(1 \mathrm{~m})$ & $\begin{array}{l}\text { Water vapour pressure at } \\
z-d=1 \mathrm{~m}\end{array}$ & $\mathrm{kPa}$ & CEH1 EC, INRA 1, UMI1 CPC \\
\hline$T\left(z_{0}^{\prime}\right)$ & $\begin{array}{l}\text { Micromet estimate of leaf } \\
\text { surface temperature }\end{array}$ & ${ }^{\circ} \mathrm{C}$ & derived from $H$ and $T(1 \mathrm{~m})$, uses $R_{b}$ for $\mathrm{H}_{2} \mathrm{O}$ \\
\hline$T$ (surf) & $\begin{array}{l}\text { Surface radiative } \\
\text { temperature }\end{array}$ & ${ }^{\circ} \mathrm{C}$ & UMIST KT19 IR Pyrometer \\
\hline$e\left(z_{0}^{\prime}\right)$ & $\begin{array}{l}\text { Water vapour pressure at } \\
\text { leaf surface }\end{array}$ & $\mathrm{kPa}$ & derived from $\lambda E$ and $e(1 \mathrm{~m})$, uses $R_{b}$ for $\mathrm{H}_{2} \mathrm{O}$ \\
\hline $\begin{array}{l}\mathrm{RH} \\
(1 \mathrm{~m})\end{array}$ & $\begin{array}{l}\text { Relative humidity at } \\
z-d=1 \mathrm{~m}\end{array}$ & $\%$ & derived from $T(1 \mathrm{~m})$ and $e(1 \mathrm{~m})$ \\
\hline $\mathrm{RH}\left(z_{0}^{\prime}\right)$ & $\begin{array}{l}\text { Relative humidity at } \\
\text { the surface }\end{array}$ & $\%$ & derived from $T\left(z_{0}^{\prime}\right)$ and $e\left(z_{0}^{\prime}\right)$ \\
\hline$R_{s b}$ & $\begin{array}{l}\text { Stomatal resistance from } \\
\text { water vapour transfer }\end{array}$ & $\mathrm{s} \mathrm{m}^{-1}$ & derived from $e\left(z_{0}^{\prime}\right), \lambda E, T\left(z_{0}^{\prime}\right)$ \\
\hline$P$ & Precipitation & $\begin{array}{l}\mathrm{mm} \\
(15 \mathrm{~min})^{-1}\end{array}$ & DWD \\
\hline$f$ & Fetch for centre of site 1 & M & derived from digitized field map and wind direction \\
\hline $\mathrm{CNF}_{\text {grad }}$ & $\begin{array}{l}\text { Commulative normalized } \\
\text { footprint function for } \\
\text { gradient measurements }\end{array}$ & $\%$ & $\begin{array}{l}\text { calculated according to Kormann and Meixner (2001), using stability corrected average height of gradient systems } \\
\text { (Haendel and Gruenhage, 1999) }\end{array}$ \\
\hline $\mathrm{CNF}_{\mathrm{EC}}$ & $\begin{array}{l}\text { Commulative normalized } \\
\text { footprint function for eddy- } \\
\text { correlation measurements }\end{array}$ & $\%$ & calculated according to Kormann and Meixner (2001) for a fixed height of $z=2.1 \mathrm{~m}-d$ \\
\hline & Atmospheric pressure & $\mathrm{kPa}$ & UMIST \\
\hline VPD (1) & $\begin{array}{l}\text { Vapour pressure deficit at } \\
z-d=1 \mathrm{~m}\end{array}$ & $\mathrm{kPa}$ & derived from $\mathrm{RH}(1 \mathrm{~m})$ and $e(1)$ \\
\hline$M$ & $\begin{array}{l}\text { Poor micrometeorological } \\
\text { condition flag }\end{array}$ & - & $\begin{array}{l}\text { Set if }(|L|<5 \mathrm{~m}) \text { or }\left(u(1 \mathrm{~m})<0.8 \mathrm{~m} \mathrm{~s}^{-1}\right) \\
\text { or }\left(\mathrm{CNF}_{E C}<67 \%\right)\end{array}$ \\
\hline$I_{m}$ & $\begin{array}{l}\text { Non-stationarity flag } \\
\text { (momentum flux) }\end{array}$ & - & Calculated according to Eqs. (20) and (21) \\
\hline$I_{H}$ & $\begin{array}{l}\text { Non-stationarity flag } \\
\text { (sensible heat flux) }\end{array}$ & - & Calculated according to Eqs. (20) and (21) \\
\hline$I_{\lambda E}$ & $\begin{array}{l}\text { Non-stationarity flag } \\
\text { (latent heat flux) }\end{array}$ & - & Calculated according to Eqs. (20) and (21) \\
\hline$I_{\mathrm{CO}_{2}}$ & $\begin{array}{l}\text { Non-stationarity flag } \\
\left(\mathrm{CO}_{2} \text { flux }\right)\end{array}$ & - & Calculated according to Eqs. (20) and (21) \\
\hline$I_{P}$ & $\begin{array}{l}\text { Non-stationarity flag } \\
\text { (precipitation) }\end{array}$ & - & Set if $P>0$ \\
\hline
\end{tabular}


respectively. In the same study data from nine different anemometers and six different fast-response water vapour sensors were also processed with a common analysis program, obtaining regressions that are in the same range as the results obtained here. This would suggest that differences in estimates are dominated by instrumentation effects than effects in processing.

The ECN data showed a large amount of scatter both for $\tau$ and $H$. As mentioned before, the ECN REA setup recorded 1-min averages of the eddy-covariance results, which had to be averaged in post-processing, a procedure that may have added further uncertainty.

Interestingly, the FAL-IUL system derived one of the largest sensible heat fluxes at the same time as it produced the smallest momentum flux. This instrument was mounted at a considerably lower measurement height than the other systems (Table 1), where the power spectrum of the turbulence is shifted towards higher frequencies. The reason for this apparent inconsistency is not fully understood, but it may suggest that momentum was on average carried by smaller and faster eddies than the heat flux. Thus, the instruments operated at higher height may have suffered some low-frequency flux loss of $H$ due to the relatively short averaging time of $15 \mathrm{~min}$, while the FAL-IUL system may have suffered highfrequency loss of $\tau$ due to the lower measurement height. In addition, the flux footprint of the FAL-IUL would have been significantly smaller and thus different to the other setups. The reason for this lower measurement height was that the FAL-IUL group wanted to test the setup as it was used back at their Swiss GRAMINAE site, where the available fetch is more restricted than at the Braunschweig site.

Significant difference were observed for the measurements of latent heat fluxes, with the INRA system, based on an IRGA deriving a lower estimate and the UMIST system, based on a Krypton Hygrometer, deriving the upper estimate. Possible reasons for the disagreement are (a) differences in the flux losses in the setups and their correction procedures and (b) differences in the absolute humidity measurement used for the calculation of fluxes from the open path sensors ( $q_{\text {ref }}$ in Eq. (20) as measured by HUMITTER probe). However, the absolute humidities that were used for the flux calculations agree much more closely than the fluxes and, unlike the fluxes, the UMIST system used slightly lower values than the INRA system. It is therefore likely that flux losses and their treatment are the main cause for the systematic differences. The Krypton hygrometer and IRGA operated by $\mathrm{CEH}$ provided very similar results, indicating that the disagreement is not simply a question of open vs. closed path sensors. The IRGA- based estimates differed possibly due to differences in flux losses in the inlet lines. However, it is currently less certain what causes the discrepancy between the two estimates based on the Krypton hygrometers. This analysis should be similar to the calculation of sensible heat fluxes which tended to be larger in the CEH setup than in the UMIST setup.
There was close agreement (within $8 \%$ ) between sites 1 and 2, implying that the field was reasonably homogeneous. In a companion paper, the comparison between $\mathrm{NH}_{3}$ flux measurements at the two sites, located at two different distances downwind of a farm, are used to quantify the effect of advection errors on $\mathrm{NH}_{3}$ flux measurements (Loubet et al., 2009). The good agreement of micrometeorological parameters suggests that differences in micrometeorological conditions between the sites on $\mathrm{NH}_{3}$ fluxes would be small.

\subsection{Aerodynamic gradient technique}

The aerodynamic gradient technique agrees reasonably well with the eddy-covariance results. The gradient results show a little more variability, with some high excursions on the FRI and CEH gradients. Most of these occurred during the period 31 May to 4 June and were correlated between the two systems, but were not reflected in the INRA gradient results. Because the footprints for the measurements at the different heights were different, gradient measurements would be more sensitive to spatial heterogeneity. The weather was hot and dry during this period, which also includes the cutting of the field, and this may have caused more spatially variable water availability and energy partitioning, until it rained again on 6 June.

However, the bulk gradient results do not show a significant systematic bias compared with the EC fluxes. This lends support to its applicability of the gradient approach to derive trace gas fluxes as used in several companion papers (Milford et al., 2009; Nemitz et al., 2009). There is some indication that the stability correction of Webb (1970), which was used under stable conditions, may have resulted in some underestimation of night-time fluxes, which would also have resulted in too small trace gas fluxes during the night.

\subsection{Energy balance closure}

The consensus dataset fails to close the energy balance closure by about $20 \%$, which is well within the range reported by other authors (e.g. Laubach and Teichmann, 1999; Wilson et al., 2002; Oliphant et al., 2004; Mauder et al., 2006). Possible reasons for non-closure that have been put forward in the literature include (a) instrumentation-related errors in the measurement of individual component fluxes, (b) conceptual problems of the micrometeorological flux measurement approach and (c) omission of further components such as storage within and above the canopy, horizontal advection and photosynthetic energy uptake by the vegetation.

The absolute closure gap in this study is of the order of $8 \mathrm{~W} \mathrm{~m}^{-2}$ at night and $60 \mathrm{~W} \mathrm{~m}^{-2}$ during daytime (Fig. 8a). Application of further flux correction changes this to $10 \mathrm{~W} \mathrm{~m}^{-2}$ at night and $50 \mathrm{~W} \mathrm{~m}^{-2}$ during the daytime, and thus accounts for only a small fraction of the residual. By comparison, Oncley et al. (2007) reported a day-time nonclosure of $70 \mathrm{~W} \mathrm{~m}^{-2}$ for an intensive closure experiment over 
irrigated cotton under higher irradiation conditions. In that study, $R_{n}$ matched $G$, while $\lambda E$ matched $H$ at night-time. While the night-time match between $R_{n}$ and $G$ is also observed at the Braunschweig grassland, here $\lambda E$ and $H$ have (on average) opposite signs during night-time. As in the study of Oncley et al. (2007) the absolute non-closure is relatively constant during daytime and does not appear to scale with the overall magnitude of the fluxes. Mauder et al. (2006) reported residuals simultaneously measured above four different adjacent land use types, with an average non-closure of $30 \%$. As with the results of Oncley et al. (2007), nighttime residuals tended to be negative, but were very small, in particular for grassland. This would be consistent with residuals being partly dominated by the omission of canopy storage in the energy balance, which would be smallest for (comparably short) grasslands.

As the array of instrumentation provides alternative answers for all parameters that feed into the assessment of the energy balance, a hypothetical alternative (maximum) estimate of the energy balance closure may be compiled by considering the maximum turbulent fluxes ( $\lambda E$ from the UMIST $\mathrm{KH} 20$ and $H$ from the FAL Gill HS anemometer) and minimum $R_{n}$ (from INRA) measured during the campaign. With these extreme values almost full closure is achieved (not shown). The $21 \%$ improvement of the energy balance in this estimate is largely due to the increase in $\lambda E(+20 \%$ compared with the consensus dataset), with smaller contributions from the increase in $H(+6 \%)$ and decrease in $R_{n}(-7 \%)$. By contrast, choosing a single of the two ground heat fluxes $(G)$ improves the energy balance only very little, because $G$ is on average much smaller than the sum of $H$ and $\lambda E$. The fact that energy budget closure can potentially be achieved by selecting individual instruments only demonstrates that the closure is within the range of the overall measurement errors. However, the evidence from other studies suggests that these extreme values do not represent the best estimate. It is more likely that the non-closure is due to methodological limitations of the current micrometeorological flux measurements approaches. For example, it has been suggested that flux can be carried by low frequencies, which are only captured by moving to much longer averaging periods of several hours, and this can be shown to improve energy closure at some forest sites (Finnigan et al., 2003). However, in practice this conflicts with changes in atmospheric conditions at this time-scale, resulting in non-stationary conditions. Interestingly, the largest $H$ was derived with the FAL setup, which was operated at the lowest measurement height, where turbulence should be faster. This would be consistent with low frequency losses at an averaging time of $15 \mathrm{~min}$ at the higher heights (where turbulence structures are larger), although this could not be substantiated by the ogive analysis conducted here (not shown). Other reasons for non-closure are weak spatial non-heterogeneities, the contribution of large stationary circulations and turbulent organized structures, which lead to vertical transport that cannot be resolved with the measurement approaches applied here (Kanda et al., 2004; Foken et al., 2006; Inagaki et al., 2006).

\subsection{Uncertainties in turbulent exchange in unreplicated measurements}

The absence of systematic biases in the measurement of momentum fluxes is extremely encouraging for the calculation of surface exchange fluxes by the aerodynamic gradient technique, where $u_{*}$ is a key parameter, equally important as the measurement of the concentration profile itself. It implies that gradient flux estimates should be equally uncertain for each 15-min, but robust if averaged over longer time-periods.

Figure 11 indicates what uncertainty (expressed as the standard deviation between replicated measurements) may be expected for $u_{*}$ and $H$, when measuring with one unreplicated setup, as would be used in most studies. The uncertainty decreases with increasing absolute value to $10 \%$ for $u_{*}$ values approaching $0.5 \mathrm{~m} \mathrm{~s}^{-1}$ and $16 \%$ for $H$ values approaching $200 \mathrm{~W} \mathrm{~m}^{-2}$. Thus, the uncertainty is not independent of the magnitude of $u_{*}$ and $H$, nor does it follow a simple hyperbolical function, suggesting that it has both an absolute and a relative component, which can be estimated by the three-parametric hyperbolical fits shown in Fig. 11. The results suggest that $u_{*}$ is subject to a relative uncertainty of $2.3 \%$, combined with an absolute uncertainty of $0.042 \mathrm{~m} \mathrm{~s}^{-1}$, while $H$ is subject to a relative uncertainty of $7.7 \%$, combined with an absolute uncertainty of $18.9 \mathrm{~W} \mathrm{~m}^{-2}$. Thus a single value of the uncertainty for $u_{*}$ or $H$, often used in the literature (e.g. Meek et al., 2005), is a poor descriptor of the true error.

There are several potential explanations for the absolute and relative components in the uncertainty in $u_{*}$ and $H$ : firstly, turbulence is a stochastic process. In addition, there are constant absolute errors associated with the measurements (e.g. resolution of the analogue/digital converters). Christen et al. (2000) also reported enhanced inter-instrument variation in $u_{*}$ between Gill Solent 1012R2 anemometers at $u_{*}<0.2 \mathrm{~m} \mathrm{~s}^{-1}$, indicating that the measurement accuracy of the wind speed makes an important contribution to the uncertainty of this anemometer. Several studies have demonstrated that the measurements of many anemometers are affected by obstructing structural elements of the anemometer itself such as transducers and supporting struts. This sheltering leads to wind direction dependent effects, which induce further scatter, but do not introduce systematic differences and are difficult to correct reliably (Hogstrom and Smedman, 2004). In addition, the coordinate rotations become less certain under calm conditions. Planar fit rotations (Wilczak et al., 2001; Finnigan et al., 2003), which may overcome this problem, were not assessed as part of this study.

Our results demonstrate that replicated measurements are most valuable when observing small fluxes. These results also have implications for the accuracy of the flux gradient 

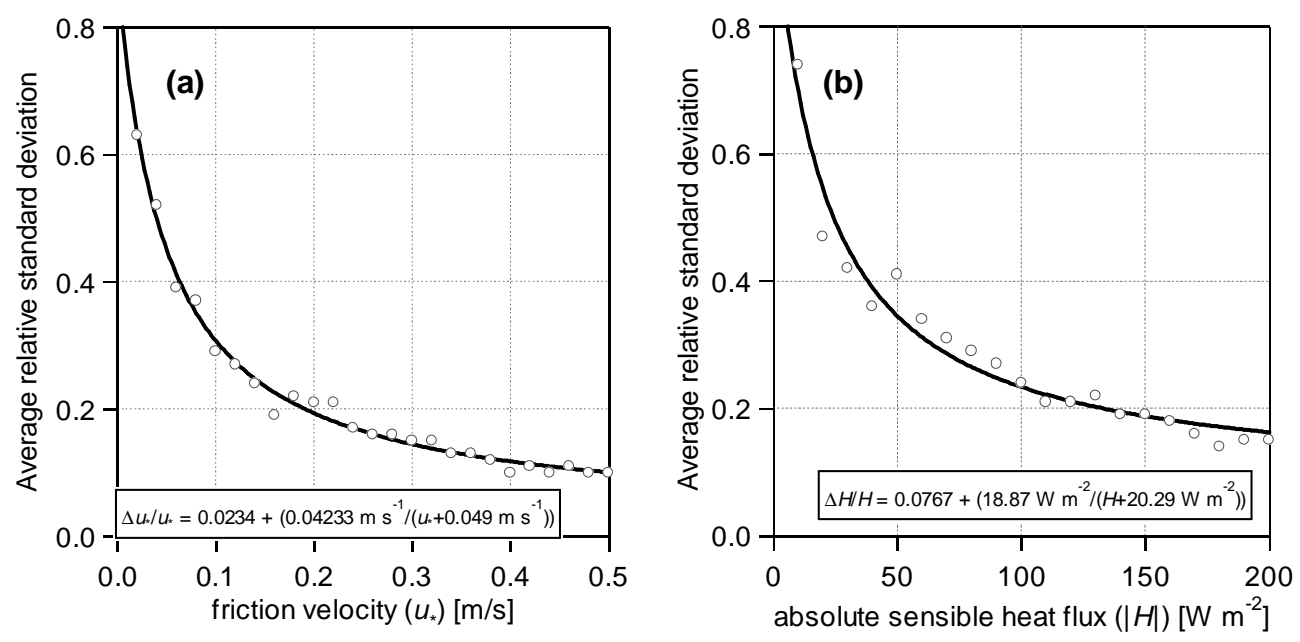

Fig. 11. Average relative standard deviations between eddy flux towers for (a) friction velocity and (b) sensible heat flux, in relation to the absolute magnitude of the values observed. The fitted hyperbolical curves provide an estimate of the relative and absolute components of the uncertainty (see text).

estimate: following Eq. (7), the relative error in the flux increases with the relative error in $u_{*}$. It should be noted, however, that in high turbulence condition the chemical gradient (and therefore $\chi_{*}$ ) is often small and subject to a large relative error due to the analytical precision.

\subsection{Uncertainties in the establishment and values of the consensus estimates}

Spatial and temporal statistical variability has been identified as the main reason for the uncertainty in individual 15-min measurements of $u_{*}$ in particular. Thus, the compilation of a consensus $u_{*}$ based on nine anemometers should have helped greatly in reducing the error of each $15 \mathrm{~min}$ measurement. The same holds true for other estimates that show random variability. For estimates that indicate clear systematic biases between setups, an individual (unbiased) measurement may in fact provide the more accurate answer than the consenus dataset. In particular, it is potentially possible that the consensus $\lambda E$ is underestimated, due to the omission of some flux corrections, and here the (higher) UMIST measurement of $\lambda E$ was suggested as an alternative estimate for the calculation of $R_{s b}$.

As statistical variability was found to be a major reason for the variability observed, the consensus dataset was calculated as the median of the different estimates rather than as the arithmetic mean. This accounts for the effect that turbulent parameters in the surface layer are log-normally distributed and it gives less weight to extreme outliers.

Figure 12 shows the time-series of an example period of the consensus values of $u(1 \mathrm{~m}), u_{*}, T(1 \mathrm{~m}), R_{n}, H$ and $\lambda E$, together with the standard errors as calculated from the statistical variation between the datapoints.

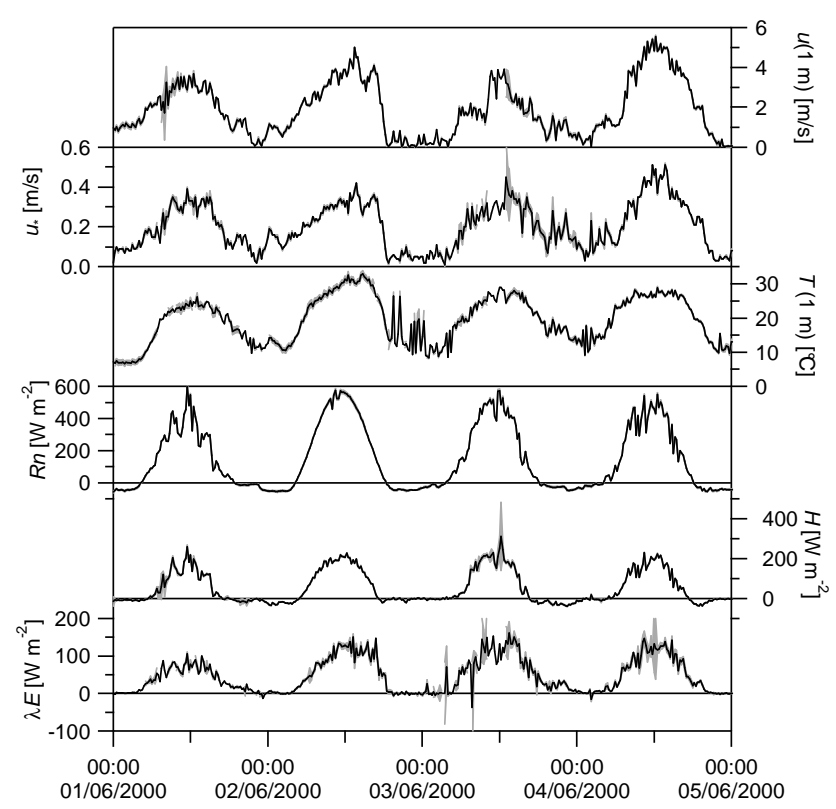

Fig. 12. Example time-series of selected parameters of the consensus dataset, together with error ranges $(+/-$ standard error).

\subsection{Uncertainties in parameters used for the parameterisation of exchange models}

Stomatal resistances and leaf temperature are important drivers for the surface atmosphere exchange of many trace compounds. The uncertainty in $\lambda E$ has important implications for the calculation and parameterisation of the bulk stomatal resistance $\left(R_{s b}\right)$. An increase in $\lambda E$ by $20 \%$ is shown to result in $R_{s b}$ which are $40 \mathrm{~m} \mathrm{~s}^{-1}$ smaller during daytime, which is similar to the magnitude of the sum of $R_{a}$ 
and $R_{b}$. This implies that, during the day, uncertainties in the atmospheric resistances are of secondary importance.

Big-leaf approaches to derive bulk stomatal resistance from heat fluxes (e.g. by the Penman-Monteith method) assume sensible and latent heat fluxes being driven by the same notional canopy temperature, $T\left(z_{0}^{\prime}\right)$. By contrast, this may not be the most appropriate temperature that governs the exchange of other trace gases such as VOCs and ammonia. A closer inspection of the temperature of different canopy elements reveals differences in leaf temperatures of up to $\approx 10^{\circ} \mathrm{C}$ during the day, and similar differences are found between the micromet estimate and a pyrometer measurement (Fig. 9). This variability in the temperature of individual surface elements has important influences on the parameterisation of trace gas exchange and the interpretation of ammonia exchange during the Braunschweig experiment: ammonia emission was observed not just after fertilisation, but also already after the cut, prior to fertilisation (Milford, 2004; Milford et al., 2009). Measurements of high ammonium concentrations in leaf litter suggest that the emission may originate from senescing plant material (Herrmann et al., 2009; Mattsson et al., 2009). The present analysis suggests that the micrometeorological estimate of the canopy temperature would tend to overestimate the day-time temperature of senescent material before the cut and underestimate this temperature after the cut.

In many situations, however, ammonia exchange is governed by the green foliage at the top of the canopy, the temperature of which appears to be overestimated by $T\left(z_{0}^{\prime}\right)$. If stomatal compensation points derived from micrometeorological measurements of $T\left(z_{0}^{\prime}\right)$ are used to estimate the ammonium concentration in the apoplast, a typical daytime overestimation of the real leaf temperature of $5^{\circ} \mathrm{C}$ would underestimate ammonium concentrations by a factor of two. Similar effects would be expected where $T\left(z_{0}^{\prime}\right)$ is used to derive temperature response curves for VOC emissions.

\section{Conclusions}

In this paper we have compared the results of micrometeorological measurements of turbulent exchange parameters, heat fluxes and parameters for modelling surface/atmosphere exchange fluxes, measured and analysed by independent laboratories, with the aim to assess typical uncertainties associated with difference in instrumentation and measurement practice. Although $u_{*}$ values of individual 15-min averaging periods can scatter significantly (median relative standard deviation of $13.9 \%$ ), especially at low wind speeds, this variability averages out in time, leading to campaign averages with a standard deviation of only $2.1 \%$. Hence, the variability is caused by spatial and temporal variability of turbulence, rather than systematic differences in instrumentation or analysis techniques. The uncertainty in 15 -min values of $u_{*}$ is a combination of a relative uncertainty of $2.3 \%$ and an absolute uncertainty of $0.042 \mathrm{~m} \mathrm{~s}^{-1}$. Variability between sen- sible heat flux $(H)$ estimates did not fully average out over time, indicating small biases between anemometers and / or analysis approaches. The uncertainty can be described as a relative uncertainty of $7.7 \%$ combined with an absolute uncertainty of $18.9 \mathrm{~W} \mathrm{~m}^{-2}$. Larger uncertainties are associated with measurements of the latent heat flux $(\lambda E)$, campaign averages of which showed a standard deviation of $17.8 \%$. The gap in the energy closure of $20 \%$ is well beyond the uncertainty in the flux corrections, suggesting that the main reason is the contribution of transport processes that are not captured by the eddy-covariance approach. However, energy closure can be achieved by selecting individual, extreme estimates, of the various components.

Of particular interest in the context of our study were the performance of the aerodynamic gradient technique and uncertainties in parameters needed to calculate fluxes by the aerodynamic gradient technique and those required to model surface/atmosphere exchange of atmospheric ammonia. The results show that ultrasonic anemometery can be robustly applied to derive the key parameters $\left(u_{*}\right.$ and $\left.H\right)$ required to establish flux gradient relationships. The comparison of gradient estimates of $u_{*}$ and $H$ compared with eddy covariance results show good agreement overall, with more variability and slightly reduced fluxes at night. Larger uncertainties are associated with other parameters needed for parameterising biospheric emissions, such as the stomatal resistance (which is derived from the latent heat fluxes) and leaf temperature estimates.

Acknowledgements. These measurements were made in the context of the EU project "GRAMINAE", while the final analysis was supported by the EU "NitroEurope IP" and national UK funding from the UK Department of Environment, Food and Rural Affairs (Defra), under the Acid Deposition Processes Project. The authors gratefully acknowledge the Institute of Agroecology of the German Federal Research Centre for Agriculture at BraunschweigVölkenrode for access to the field site and provision of excellent site infrastructure.

Edited by: J. K. Schjoerring

\section{References}

Aubinet, M., Grelle, A., Ibrom, A., Rannik, Ü., Moncrieff, J., Foken, T., Kowalski, A. S., Martin, P. H., Berbigier, P., Bernhofer, C., Clement, R., Elbers, J., Granier, A., Grunwald, T., Morgenstern, K., Pilegaard, K., Rebmann, C., Snijders, W., Valentini, R., and Vesala, T.: Estimates of the annual net carbon and water exchange of forests: The EUROFLUX methodology, Adv. Ecol. Res., 30, 113-175, 2000.

Barr, A. G., Morgenstern, K., Black, T. A., McCaughey, J. H., and Nesic, Z:: Surface energy balance closure by the eddycovariance method above three boreal forst stands and implications for the measurement of the $\mathrm{CO}_{2}$ flux, Agr. Forest Meteorol., 140, 322-337, doi:10.1016/j.agrformet.2006.08.007, 2006.

Burkhardt, J., Flechard, C. R., Gresens, F., Mattsson, M., Jongejan, P. A. C., Erisman, J. W., Weidinger, T., Meszaros, R., Nemitz, E., 
and Sutton, M. A.: Modelling the dynamic chemical interactions of atmospheric ammonia with leaf surface wetness in a managed grassland canopy, Biogeosciences, 6, 67-83, 2009, http://www.biogeosciences.net/6/67/2009/.

Christen, A., van Gorsel, E., Andretta, M., Calanca, P., Rotach, M. W., and Vogt, R.: Intercomparison of ultrasonic anemometers during the MAP Riviera project, Ninth Conference on Mountain Meteorology, 7-12 August 2000, Aspen, Colorado, 2000.

Dämmgen, U., Grünhage, L., and Schaaf, S.: The precision and spatial variability of some meteorological parameters needed to determine vertical fluxes of air constituents, Landbauforschung Volkenrode, 55, 29-37, 2005.

Dutaur, L., Cieslik, S., Carrara, A., and Lopez, A.: The Detection of Nonstationarity in the Determination of Deposition Fluxes, Eurotrac, Garmisch-Partenkirchen; Germany, 171-176, CN030443471, 1998.

Dyer, A. J. and Hicks, B. B.: Flux-gradient relationships in the constant flux layer, Q. J. Roy. Meteor. Soc., 96, 715-721, 1970.

Dyer, A. J., Garratt, J. R., Francey, R. J., McIlroy, I. C., Bacon, N. E., Hyson, P., Bradley, E. F., Denmead, O. T., Tsvang, L. R., Volkov, Y. A., Koprov, B. M., Elagina, L. G., Sahashi, K., Monji, N., Hanafusa, T., Tsukamoto, O., Frenzen, P., Hicks, B. B., Wesely, M., Miyake, M., and Shaw, W.: An International Turbulence Comparison Experiment (Itce 1976), Bound.-Lay. Meteorol., 24, 181-209, 1982.

Finnigan, J. J., Clement, R., Malhi, Y., Leuning, R., and Cleugh, H. A.: A re-evaluation of long-term flux measurement techniques. Part I: Averaging and coordinate rotation, Bound.-Lay. Meteorol., 107, 1-48, 2003.

Flechard, C. R. and Fowler, D.: Atmospheric ammonia at a moorland site. II: Long-term surface- atmosphere micrometeorological flux measurements, Q. J. R. Meteor. Soc., 124, 759-791, 1998.

Foken, T., Wimmer, F., Mauder, M., Thomas, C., and Liebethal, C.: Some aspects of the energy balance closure problem, Atmos. Chem. Phys., 6, 4395-4402, 2006, http://www.atmos-chem-phys.net/6/4395/2006/.

Foken, T.: Micrometeorology, Sprinter, 308 pp., 2008.

Fritschen, L. J., Qian, P., Kanemasu, E. T., Nie, D., Smith, E. A., Stewart, J. B., Verma, S. B., and Wesely, M. L.: Comparisons of Surface Flux Measurement Systems Used in Fife 1989, J. Geophys. Res.-Atmos., 97, 18697-18713, 1992.

Garland, J. A.: Dry Deposition of Sulfur-Dioxide to Land and Water Surfaces, P. Roy. Soc. A-Math. Phy., 354, 245-268, 1977.

Guenther, A., Karl, T., Harley, P., Wiedinmyer, C., Palmer, P. I., and Geron, C.: Estimates of global terrestrial isoprene emissions using MEGAN (Model of Emissions of Gases and Aerosols from Nature), Atmos. Chem. Phys., 6, 3181-3210, 2006, http://www.atmos-chem-phys.net/6/3181/2006/.

Hammerle, A., Haslwanter, A., Schmitt, M., Bahn, M., Tappeiner, U., Cernusca, A., and Wohlfahrt, G.: Eddy covariance measurements of carbon dioxide, latent and sensible energy fluxes above a meadow on a mountain slope, Bound.-Lay. Meteorol., 122, 397-416, 2007.

Hensen, A., Nemitz, E., Flynn, M. J., Blatter, A., Jones, S. K., Srensen, L. L., Hensen, B., Pryor, S., Jensen, B., Otjes, R. P., Cobussen, J., Loubet, B., Erisman, J. W., Gallagher, M. W., Neftel, A., and Sutton, M. A.: Inter-comparison of ammonia fluxes obtained using the relaxed eddy accumulation technique, Bio- geosciences Discuss., 5, 3965-4000, 2008, http://www.biogeosciences-discuss.net/5/3965/2008/.

Hensen, A., Loubet, B., Mosquera, J., van den Bulk, W. C. M., Erisman, J. W., Dämmgen, U., Milford, C., Löpmeier, F. J., Cellier, P., Mikuška, P., and Sutton, M. A.: Estimation of $\mathrm{NH}_{3}$ emissions from a naturally ventilated livestock farm using local-scale atmospheric dispersion modelling, Biogeosciences Discuss., 6, 825862, 2009, http://www.biogeosciences-discuss.net/6/825/2009/.

Herrmann, B., Mattsson, M., Jones, S. K., Cellier, P., Milford, C., Sutton, M. A., Schjoerring, J. K., and Neftel, A.: Vertical structure and diurnal variability of ammonia exchange potential within an intensively managed grass canopy, Biogeosciences, 6 , 15-23, 2009, http://www.biogeosciences.net/6/15/2009/.

Hogstrom, U. and Smedman, A.-S.: Accuracy of sonic anemometers: laminar wind-tunnel calibrations compared to atmospheric in situ calibrations against a reference instrument, Bound.-Lay. Meteorol., 111, 33-54, 2004.

Horst, T. W.: A simple formula for attenuation of eddy fluxes measured with first-order-response scalar sensors, Bound.-Lay. Meteorol., 82, 219-233, 1997.

Inagaki, A., Letzel, M. O., Raasch, S., and Kanda, M.: The impact of the surface heterogeneity on the energy imbalance: a study using LES, J. Meteorol. Soc. Jpn., 84, 187-198, 2006.

Jarvis, P. G.: The interpretation of the variation in leaf water potential and stomatal conductance found in canopies in the field, Philos. T. R. Soc. Lond., B273, 593-610, 1976.

Kaimal, J. C. and Finnigan, J. J.: Atmospheric boundary layer flows, Oxford University Press, New York, 1994.

Kanda, M., Inagaki, A., Letzel, M. O., Raasch, S., and Watanabe, T.: LES study of the energy imbalance problem with eddy covariance fluxes, Bound.-Lay. Meteorol., 110, 381-404, 2004.

Kormann, R. and Meixner, F. X.: An analytical footprint model for non-neutral stratification, Bound.-Lay. Meteorol., 99, 207-224, 2001.

Laubach, J. and Teichmann, U.: Surface energy budget variability: A case study over grass with special regard to minor inhomogeneities in the source area, Theor. Appl. Climatol., 62, 9-24, 1999.

Loubet, B., Milford, C., Hensen, A., Daemmgen, U., Erisman, J.W., Cellier, P., and Sutton, M. A.: Advection of $\mathrm{NH}_{3}$ over a pasture field and its effect on gradient flux measurements, Biogeosciences, 6, 1295-1309, 2009, http://www.biogeosciences.net/6/1295/2009/.

Mattsson, M., Herrmann, B., David, M., Loubet, B., Riedo, M., Theobald, M. R., Sutton, M. A., Bruhn, D., Neftel, A., and Schjoerring, J. K.: Temporal variability in bioassays of the stomatal ammonia compensation point in relation to plant and soil nitrogen parameters in intensively managed grassland, Biogeosciences, 6, 171-179, 2009, http://www.biogeosciences.net/6/171/2009/.

Mauder, M. and Foken, T.: Ergebnisse verschiedener Turbulenzmessgeraetevergleiche, University of Bayreuth, Department for micrometeorology, Bayreuth, Germany, 2001.

Mauder, M., Liebethal, C., Goedecke, M., Leps, J.-P., Beyrich, F., and Foken, T.: Processing and quality control of flux data during LITFASS-2003, Bound.-Lay. Meteorol., 121, 67-88, 2006.

Mauder, M., Oncley., S. P., Vogt, R., Weidinger, T., Ribeiro, L., Bernhofer, C., Foken, T., Kohsiek, W., de Bruin, H. A. R., and Liu, H.: The energy blance experiment ebex-2000. Part II: Inter- 
comparison of eddy-covariance sensors and post-field data processing methods, Bound.-Lay. Meteorol., 123, 29-54, 2007.

Mauder, M., Foken, T., Clement, R., Elbers, J. A., Eugster, W., Grünwald, T., Heusinkveld, B., and Kolle, O.: Quality control of CarboEurope flux data - Part 2: Inter-comparison of eddycovariance software, Biogeosciences, 5, 451-462, 2008, http://www.biogeosciences.net/5/451/2008/.

McMillen, R. T.: An eddy correlation technqiue with extended applicability to non-simple terrain, Bound.-Lay. Meteorol., 43, 231-245, 1988.

Meek, D. W., Prueger, J. H., Kustas, W. P., and Hatfield, J. L.: Determining meaningful differences for SMACEX eddy covariance measurements, J. Hydrometeorol., 6, 805-811, 2005.

Mészáros, R., Horváth, L., Weidinger, T., Neftel, A., Nemitz, E., Dämmgen, U., Cellier, P., and Loubet, B.: Measurement and modelling ozone fluxes over a cut and fertilized grassland, Biogeosciences Discuss., 6, 1069-1089, 2009, http://www.biogeosciences-discuss.net/6/1069/2009/.

Milford, C.: Dynamics of Atmospheric Ammonia Exchange with Intensively-Managed Grassland, School of Geosciences, University of Edinburgh, Edinburgh, 2004.

Milford, C., Theobald, M. R., Nemitz, E., Hargreaves, K. J., Horvath, L., Raso, J., Dämmgen, U., Neftel, A., Jones, S. K., Hensen, A., Loubet, B., Cellier, P., and Sutton, M. A.: Ammonia fluxes in relation to cutting and fertilization of an intensively managed grassland derived from an inter-comparison of gradient measurements, Biogeosciences, 6, 819-834, 2009,

http://www.biogeosciences.net/6/819/2009/.

Moncrieff, J. B., Massheder, J. M., de Bruin, H., Elbers, J., Friborg, T., Heusinkveld, B., Kabat, P., Scott, S., Soegaard, H., and Verhoef, A.: A system to measure surface fluxes of momentum, sensible heat, water vapour and carbon dioxide, J. Hydrol., 189, 589-611, 1997.

Nemitz, E., Milford, C., and Sutton, M. A.: A two-layer canopy compensation point model for describing bi-directional biosphere-atmosphere exchange of ammonia, Q. J. Roy. Meteorol. Soc., 127, 815-833, 2001.

Nemitz, E., Hargreaves, K. J., McDonald, A. G., Dorsey, J. R., and Fowler, D.: Micrometeorological measurements of the urban heat budget and $\mathrm{CO}_{2}$ emissions on a city scale, Environ. Sci. Technol., 36, 3139-3146, 2002.

Nemitz, E., Dorsey, J. R., Flynn, M. J., Gallagher, M. W., Hensen, A., Erisman, J.-W., Owen, S. M., Dämmgen, U. and Sutton, M. A.: Aerosol fluxes and particle growth above managed grassland, Biogeosciences, accepted, 2009.

Oliphant, A. J., Grimmond, C. S. B., Zutter, H. N., Schmid, H. P., Su, H.-B., Scott, S. L., Offerle, B., Randolph, J. C., and Ehman, J.: Heat storage and energy balance fluxes for a temperate decidious forest, Agr. Forest Meteorol., 126, 185-201, 2004.

Oncley, S. P., Foken, T., Vogt, R., Kohsiek, W., DeBruin, H. A. R., Bernhofer, C., Christen, A., van Gorsel, E., Grantz, D., Feigenwinter, C., Lehner, I., Liebethal, C., Liu, H., Mauder, M., Pitacco, A., Ribeiro, L., and Weidinger, T.: The energy balance experiment EBEX-2000. Part I: overview and energy closure, Bound.-Lay. Meteorol., 123, 1-28, 2007.

Owen, P. R. and Thompson, W. R.: Heat transfer across rough surfaces, J. Fluid Mech., 15, 321-334, 1963.

Personne, E., Loubet, B., Herrmann, B., Mattsson, M., Schjoerring, J. K., Nemitz, E., Sutton, M. A., and Cellier, P.: SURFATM-
NH3: a model combining the surface energy balance and bidirectional exchanges of ammonia applied at the field scale, Biogeosciences, 6, 1371-1388, 2009, http://www.biogeosciences.net/6/1371/2009/.

Schotanus, P., Nieuwstadt, F. T. M., and DeBruin, H. A. R.: Temperature measurement with a sonic anemometer and its application to heat and moisture fluctuations, Bound.-Lay. Meteorol., 26, 81-93, 1983.

Shuttleworth, W. J. and Wallace, J. S.: Evaporation from sparse crop - an energy combination theory, Q. J. Roy. Meteor. Soc., 111, 839-855, 1985.

Sutton, M. A., Fowler, D., and Moncrieff, J. B.: The Exchange of Atmospheric Ammonia with Vegetated Surfaces. 1. Unfertilized Vegetation, Q. J. Roy. Meteor. Soc., 119, 1023-1045, 1993.

Sutton, M. A., Schjorring, J. K., and Wyers, G. P.: Plant Atmosphere Exchange of Ammonia, Philos. T. R. Soc. Lond., 351, 261-276, 1995.

Sutton, M. A., Burkhardt, J. K., Guerin, D., Nemitz, E., and Fowler, D.: Development of resistance models to describe measurements of bi-directional ammonia surface-atmosphere exchange, Atmos. Environ., 32, 473-480, 1998.

Sutton, M. A., Milford, C., Nemitz, E., Theobald, M. R., Hill, P. W., Fowler, D., Schjoerring, J. K., Mattsson, M. E., Nielsen, K. H., Husted, S., Erisman, J. W., Otjes, R., Hensen, A., Mosquera, J., Cellier, P., Loubet, B., David, M., Genermont, S., Neftel, A., Blatter, A., Herrmann, B., Jones, S. K., Horvath, L., Fuhrer, E. C., Mantzanas, K., Koukoura, Z., Gallagher, M., Williams, P., Flynn, M., and Riedo, M.: Biosphere-atmosphere interactions of ammonia with grasslands: Experimental strategy and results from a new European initiative, Plant Soil, 228, 131-145, 2001.

Sutton, M. A., Nemitz, E., Milford, C., Campbell, C., Erisman, J. W., Hensen, A., Cellier, P., David, M., Loubet, B., Personne, E., Schjoerring, J. K., Mattsson, M., Dorsey, J. R., Gallagher, M. W., Horvath, L., Weidinger, T., Meszaros, R., Dämmgen, U., Neftel, A., Herrmann, B., Lehman, B. E., Flechard, C., and Burkhardt, J.: Dynamics of ammonia exchange with cut grassland: synthesis of results and conclusions of the GRAMINAE Integrated Experiment, Biogeosciences Discuss., 6, 1121-1184, 2009a, http://www.biogeosciences-discuss.net/6/1121/2009/.

Sutton, M. A., Nemitz, E., Theobald, M. R., Milford, C., Dorsey, J. R., Gallagher, M. W., Hensen, A., Jongejan, P. A. C., Erisman, J. W., Mattsson, M., Schjoerring, J. K., Cellier, P., Loubet, B., Roche, R., Neftel, A., Hermann, B., Jones, S. K., Lehman, B. E., Horvath, L., Weidinger, T., Rajkai, K., Burkhardt, J., Löpmeier, F. J., and Daemmgen, U.: Dynamics of ammonia exchange with cut grassland: strategy and implementation of the GRAMINAE Integrated Experiment, Biogeosciences, 6, 309-331, 2009b, http://www.biogeosciences.net/6/309/2009/.

Tsvang, L. R., Zubkovskii, S. L., Kader, B. A., Kallistratova, M. A., Foken, T., Gerstmann, V., Przadka, A., Pretel, Y., Zeleny, Y., and Keder, J.: International Turbulence Comparison Experiment (Itce-81), Bound.-Lay. Meteorol., 31, 325-348, 1985.

van Dijk, A., Kohsiek, W., and DeBruin, H. A. R.: Oxygen sensitivity of krypton and Lyman-alpha hygrometers, J. Atmos. Ocean. Tech., 20, 143-151, 2003.

Webb, E. K.: Profile relationships: the log-linear range and extension to strong stability, Q. J. Roy. Meteor. Soc., 96, 67-90, 1970.

Webb, E. K., Pearman, G. I., and Leuning, R.: Correction of flux measurements for density effects due to heat and water vapour 
transfer, Q. J. Roy. Meteor. Soc., 106, 85-100, 1980.

Wesely, M. L. and Hicks, B. B.: Some factors that affect the deposition rates of sulfur dioxide and similar gases on vegeation, JAPCA J. Air Waste Ma., 27, 1110-1116, 1977.

Wieser, A., Fiedler, F., and Corsmeier, U.: The influence of the sensor design on wind measurements with sonic anemometer systems, J. Atmos. Ocean. Tech., 18, 1585-1608, 2001.

Wilczak, J., Oncley, S., and Stage, S. A.: Sonic anemometer tilt correction algorithms, Bound.-Lay. Meteorol., 99, 127-150, 2001.
Wilson, K., Goldstein, A., Falge, E., Aubinet, M., Baldocchi, D., Berbigier, P., Bernhofer, C., Ceulenmans, R., Dolman, H., Field, C., Grelle, A., Ibrom, A., Law, B. E., Kowalski, A., Meyers, T., Moncrieff, J., Monson, R., Oechel, W., Tenhunen, J., Valentini, R., and Verma, S.: Energy balance closure at FLUXNET sites, Agr. Forest Meteorol., 113, 223-243, 2002. 